\title{
Latent Heat Nudging in the Canadian Regional Deterministic Prediction System
}

\author{
Dominik Jacques, Daniel Michelson, JeAn-François CARon, And Luc Fillion \\ Environment and Climate Change Canada, Dorval, Québec, Canada
}

(Manuscript received 6 April 2018, in final form 27 August 2018)

\begin{abstract}
This study reports on the progress toward operational weather radar data assimilation in Canada. As a first step, the latent heat nudging (LHN) technique has been tested for a period of 1 month. It is the first time that LHN is used across the North American continent, a domain significantly larger than that of other LHN studies. Other novel aspects of this study include the use of a quality index associated with individual reflectivity measurements and a discussion on matching the effective resolution of the modeled precipitation for a reduction of the representation errors. Various verification scores indicate that LHN has a positive influence on instantaneous precipitation rates for lead times up to $3 \mathrm{~h}$. In comparison, the nowcasting of precipitation rates by a simple Lagrangian extrapolation method yields improvements that last up to approximately $4 \mathrm{~h}$. Verifications against aircraft measurements indicate small but statistically significant improvements throughout the troposphere for lead times up to $24 \mathrm{~h}$.
\end{abstract}

\section{Introduction}

This article reports on the assimilation of reflectivity measurements from weather radars through the adjustment of latent heating in the model. Weather radars operate by transmitting pulses of electromagnetic waves and measuring the characteristics of the signal that is backscattered to the instrument. The equivalent reflectivity factor, here "reflectivity" for short, is related to the intensity of the returned signal (Doviak and Zrnic 1993; Fabry 2015). For many practical applications, reflectivity is considered as a proxy for precipitation without too much consideration for its quantitative meaning. Precipitation has such a large influence on human activities that even this informal interpretation of reflectivity is of high value. To a forecaster, an animated map of radar reflectivity conveys precious information on the location of precipitation, the presence of convection, its state of development, and its displacement velocity. This information is valuable enough that relatively simple extrapolation algorithms (Germann and Zawadzki 2002; Turner et al. 2004; Ruzanski et al. 2011; among others) are used to predict the occurrence of precipitation at very short lead times.

For some applications, however, the quantitative nature of reflectivity must be taken into account. One such

Corresponding author: Dominik Jacques, dominik.jacques@ canada.ca application is data assimilation. In this context, radar reflectivity is a challenging observation. Errico et al. (2007) enumerate the factors making this measurement difficult to assimilate. Chief among them is the highly nonlinear nature of the equations governing the evolution of clouds and precipitation. In the variational context, these nonlinearities have been addressed by use of various simplifying assumptions. Some have considered only warm rain processes (Sun and Crook 1997, 1998; Chung et al. 2009) or used "linearized" physical parameterizations for the derivation of adjoint equations [as discussed in section 4c of Errico et al. (2007)]. It must also be noted that the parameterization of microphysical processes (explicit or not) are subject to errors, which can lead to systematic differences between the simulated and the observed atmosphere.

The statistical distribution of microphysical quantities, usually non-Gaussian and bounded at zero, complicates the assimilation of radar reflectivity. Because of this, the assimilation is sometimes restricted to the locations where precipitation is both simulated and observed (Lopez 2011).

When the assimilation is performed in an ensemble context (such as with the ensemble Kalman filter), the strong nonlinearities manifest themselves as a weakening of the spatial correlations being estimated. Significant reductions of the correlation lengths in the presence of convection have also been documented (Chung et al. 2013; Jacques and Zawadzki 2015). 
The very nature of reflectivity measurements ${ }^{1}$ imposes a high degree of uncertainty to any forward operator formulation. Yet another factor complicating the assimilation of radar reflectivity is the domination of the measured signal by high-energy/small-scale phenomena such as convective plumes/bubbles. These features are not well captured in background estimates, which make them somewhat incompatible with the observations. ${ }^{2}$ Finally, other issues such as beam propagation, calibration, and contamination by nonmeteorological targets complicate the matter.

Despite all these difficulties, radar reflectivities are assimilated by a number of operational centers. Of note is the operational assimilation of accumulated precipitation over the contiguous United States in the 4DVAR assimilation system operated by the European Centre for Medium-Range Weather Forecasts (ECMWF; Lopez 2011). An interesting contribution of this work is the demonstration that long accumulation periods $(6 \mathrm{~h})$ alleviate the problems associated with nonlinearities and improve the validity of the approximations made in the adjoint model. ECMWF's assimilation of reflectivity with 4DVAR followed a previous effort using a 1D+4DVAR approach (Lopez and Bauer 2007). A similar technique was adopted at Météo-France (Wattrelot et al. 2014), which implemented a $1 \mathrm{D}+3 \mathrm{DVAR}$ system. In this system, vertical profiles of moisture are first inferred from reflectivity using a Bayesian approach. The recovered moisture is then assimilated, along with other measurements, using 3DVAR. Recently, this technique has been used in a proof-of-concept study toward multinational radar data assimilation in Europe (Ridal and Dahlbom 2017).

If one is willing to use less formal, indirect techniques, the assimilation of reflectivity becomes much easier. To this end, a number of "diabatic initialization methods" [listed by Sun et al. (2014)] have been proposed. In this framework, temperature and/or moisture is modified for a better match between the observed and modeled precipitation. For example,

\footnotetext{
${ }^{1}$ In rain, reflectivity is related to the sixth moment of dropsize distributions (Doviak and Zrnić 1993) and can be associated to water content through various $Z-R$ relationships (e.g., Battan 1973). In the presence of ice crystals, aggregates, and melting particles, the situation is more complicated, and relationships with water content become more uncertain (Fabry 2015).

${ }^{2}$ Even at resolutions that allow the representation of convective plumes/bubbles by the models, their low predictability makes it very difficult to obtain background estimates where the convection is collocated (in time and space) with radar observations.
}

Wang et al. (2014) propose a technique where moisture is adjusted based on reflectivity observations. In the Rapid Refresh (RAP) and the High-Resolution Rapid Refresh (HRRR), latent heating is prescribed by $3 \mathrm{D}$ reflectivity observations at the beginning of forecasts (Weygandt and Benjamin 2007; Weygandt et al. 2008; Alexander et al. 2017).

Of all diabatic initialization techniques, latent heat nudging (LHN; Wang and Warner 1988; Manobianco et al. 1994; Jones and Macpherson 1997) is probably the most popular method for assimilating radar reflectivity in operational systems. It has been used operationally at the Met Office since 1996, and it has been well documented (Dixon et al. 2009; Ballard et al. 2016; Simonin et al. 2017). Similarly, LHN has been operational at Deutscher Wetterdienst (DWD) since 2007 (Stephan et al. 2008). LHN has also been used for research (Davolio and Buzzi 2004; Leuenberger and Rossa 2007).

While Canada has a long history of research in the field of radar meteorology (Douglas 1990) and has been operating a network comprising C-band and S-band Doppler radars since the 1990s, these measurements have never been assimilated operationally.

Two reasons motivate the present effort toward the operational assimilation of radar data. First is the planned transformation of the current Regional Deterministic Prediction System (RDPS; Caron et al. 2015) into a continuously cycled system operating at the convective scale. In a continuously cycled system, forecasts are initialized with previous analyses from the same system. This allows for short spinup times for precipitation. In this context, it becomes desirable to assimilate radar data to improve short-term precipitation forecasts. Second is the renewal of the Canadian radar network, where C-band radars are being replaced by polarimetric S-band radars. The new instruments will allow for higher-quality data and the measurements of Doppler velocity at ranges of $240 \mathrm{~km}$ (compared to $112 \mathrm{~km}$ for the current C-band radars). The present study lays the foundation that will allow us to use the new radars to their maximum potential.

LHN was chosen as a first step toward radar data assimilation in a Canadian system. It is relatively simple to implement and can be run at low additional cost to the existing assimilation system. LHN also offers reasonable performance, compared to other assimilation methods (Sun 2005; Wilson et al. 2010; Sun et al. 2014; Bick et al. 2016). Irrespective of the approaches that may be tested in the future, it will be relevant to conduct comparisons against the LHN system developed here. Finally, the data infrastructure that is put in place for LHN will also benefit other radar data assimilation projects. 
While this study reports on the implementation of a known method in an operational system, it also pursues the following research objectives:

- One hypothesis being tested is whether applying LHN over a large domain could result in improved precipitation forecasts for durations longer than a few hours. To this end, radar measurements from Canada, the continental United States, and Alaska have been assimilated. It seems reasonable to suppose that applying LHN on this continental-scale domain could improve the large-scale atmospheric flow, which would lead to longer-lasting improvements to precipitation forecasts. Two aspects of this hypothesis are investigated:

- First, we verify the skill of precipitation forecast as a function of lead time. This is done using conventional approaches and scale-decomposition techniques. Such decompositions allow us to assess the scales upon which LHN act and the rate at which skill decreases as a function of scale.

- Second, we examine how LHN influences the largescale atmospheric flow. This is done through the verification of dynamic variables such as wind and temperature throughout the atmospheric column.

- The representation errors associated with radar reflectivity are explicitly acknowledged and accounted for. These errors are minimized through the processing of radar observations for a better correspondence between the effective resolution of modeled precipitation and that of the measurements.

- A few modifications are made to the original approach of Jones and Macpherson (1997). These modifications contribute to the incremental advancement of knowledge related to this technique.

- First is the use of an observation-based qualitative quality index to modulate the intensity of LHN at each model grid point.

- Second is the determination of "initiating profiles" whose purpose is to stimulate the model in generating precipitation where it is observed but not simulated.

- Finally, the performance of LHN is compared to that of simple extrapolation nowcasts.

While not a research objective in itself, another unique aspect of this work is the application of open software for the decoding, quality control, and compositing of radar data at the continental scale.

This paper is organized as follows. The observations are discussed in section 2. The assimilation system is then portrayed in section 3 , followed by a step-bystep description of the LHN algorithm in section 4 . The MAPLE algorithm used to obtain the extrapolation nowcasts is outlined in section 5 , while section 6 discusses the verification of forecasts. The results are

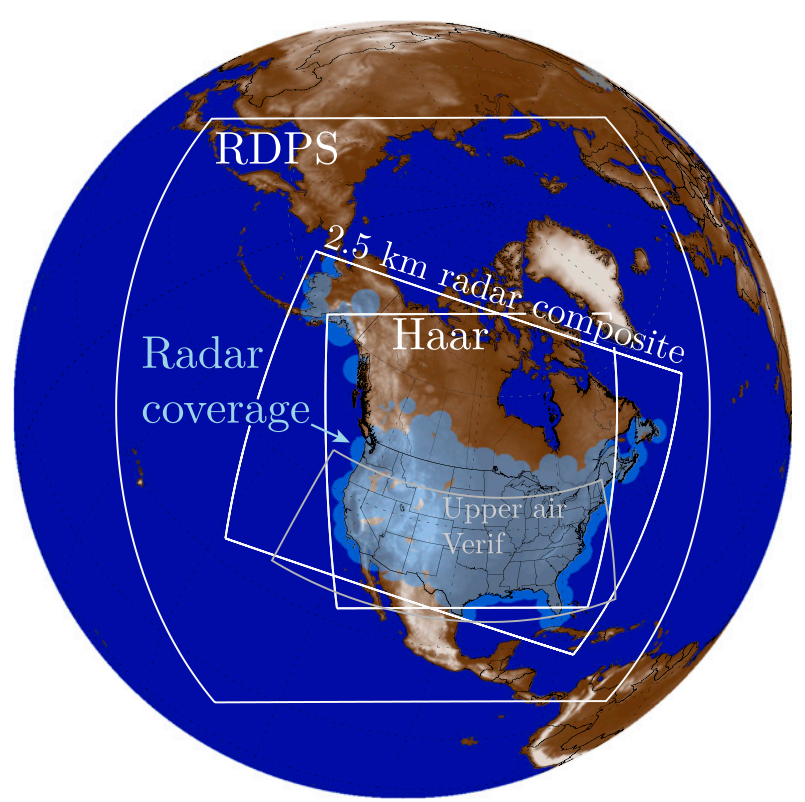

FIG. 1. Domains used for the integration of the RDPS, the 2.5-km radar composites, the computation of Haar wavelets, and the upper-air forecast verifications. The radar coverage is indicated in light blue shadings.

discussed in section 7, and concluding remarks are found in section 8 .

\section{Observations}

The product assimilated in this study consists of radarinferred precipitation rates on the 10-km RDPS grid (shown in Fig. 1). This section describes the process by which the reflectivity measurements from many radars (available in spherical coordinates) are transformed into precipitation rates on a two-dimensional Cartesian grid. This transformation is performed in two distinct steps.

The first step, described in section $2 \mathrm{a}$, consists of instrument-based processing where the measurements from all the available radars are quality controlled and combined on a continental-scale grid. The outcome of this step is an intermediate $2.5-\mathrm{km}$ reflectivity composite where each pixel is assigned a quality index indicating the level of confidence for this measurement.

The second step, described in section $2 b$, consists of model-based processing. During this process, the intermediate $2.5-\mathrm{km}$ reflectivity composites are converted to precipitation rates on the $10-\mathrm{km}$ model grid. It is these precipitation rates, along with the associated quality indexes, that are used in the assimilation.

\section{a. Instrument-based processing}

Weather radar data from three sources are used in this study: 
1) Environment and Climate Change Canada (ECCC)'s weather radar network consisting of $30 \mathrm{C}$-band Doppler radars. Data are acquired using a 10-min cycle that starts with a 24-sweep volume containing only uncorrected reflectivities (i.e., no Doppler signal processing). Maximum range is $256 \mathrm{~km}$, with a resolution of $1 \mathrm{~km}$ in range and $1^{\circ}$ in azimuth. This first volume is followed up by three dedicated sweeps where both reflectivity and radial wind velocity are measured. For these sweeps, the maximum range is $112.5 \mathrm{~km}$, with a resolution of $500 \mathrm{~m}$ in range and $0.5^{\circ}$ in azimuth.

2) McGill University's S-band dual-polarization radar located west of Montréal. While this is a radar designed and used for research purposes, it is run operationally to contribute data to ECCC's network. For this radar, the maximum range is $480 \mathrm{~km}$, with a variable resolution in range $(1-4 \mathrm{~km})$ and $1^{\circ}$ in azimuth.

3) The U.S. Next Generation Weather Radar (NEXRAD) network of S-band dual-polarization radars. The "level II" product from all the radars in the contiguous United States and Alaska has been used for this study. Data are generally acquired with a cycle of around $6 \mathrm{~min}$. The maximum range is $458 \mathrm{~km}$, with a resolution of $250 \mathrm{~m}$ in range and $0.5^{\circ}$ in azimuth. In this study, NEXRAD data have been used to a maximum range of $250 \mathrm{~km}$.

The software framework for applying quality controls and generating composite (mosaic) products is the BALTRAD $^{3}$ toolbox (Michelson et al. 2018). The $2.5-\mathrm{km}$ reflectivity composites are obtained by first harmonizing all polar data to a common file format (in this case, ODIM_H5; Michelson et al. 2014) and then combining data from the different radars onto a common grid.

Decoding the proprietary IRIS format of the Canadian data and the in-house format of the McGill radar required that new functionality be added to the BALTRAD toolbox. The NEXRAD data were decoded using functionality found in Py-ART software (Helmus and Collis 2016).

While the data are converted from one format to another, various quality controls are also applied. These quality controls each define a quality indicator on the same polar grid as the sweep of data and, in most cases, also correct the reflectivities. The value of the quality indicator ranges between 0 (lowest quality) and 1 (highest quality). In this study, a combined "total

\footnotetext{
${ }^{3}$ The name BALTRAD originates from the fact that it was developed to network weather radar data in the Baltic Sea region.
}

quality" indicator is used in the compositing algorithm, the assimilation process, and the verification of results. It is thus worthwhile to describe the quality-control processing chain from which it originates:

1) An ECCC in-house algorithm is applied to the data from the Canadian network. This step is necessary since the 256-km Canadian data are effectively nonDoppler reflectivities with significant clutter contamination. The decluttering algorithm combines the 256-km non-Doppler data with the shorter-range $(112.5 \mathrm{~km})$ Doppler data and vertical structure analyses to yield a lowest sweep of quality-controlled reflectivity.

2) A hit-accumulation clutter filter is also applied to the data from the Canadian network. With this filter, echoes are removed if their monthly frequency of occurrence exceeds $60 \%$. Such polar bins are marked with the "no data" special value, and the corresponding quality indicator is set to zero. The "no data" special value is used to represent areas that have not been radiated.

3) The identification and removal of nonprecipitation echoes is performed according to Peura (2002). This algorithm identifies biometeor targets (birds, insects), speckle, and external emitters (e.g., radio interference). These echoes are assigned the "undetect" special value with a quality indicator set to the estimated probability of the echo being nonprecipitation. The "undetect" special value represents areas that have been radiated but that have not produced detectable echoes.

4) Beam-blockage identification and correction is performed using the GTOPO30, a $\sim 1-\mathrm{km}$ global digital elevation model produced by the U.S. Geological Survey. ${ }^{4}$ While the measurements with partial blockage up to $60 \%$ are corrected, those with blockage exceeding $60 \%$ are assigned the "no data" special value. For this quality control, the quality index is set to the estimated percentage of beam blockage.

5) Conventional attenuation correction is performed according to Ośródka et al. (2014). The quality index for this quality control diminishes for stronger pathintegrated attenuation.

6) The algorithm by Ośródka et al. (2014) assigns a quality indicator that describes the decrease in data quality that occurs as the radar beam broadens with increasing range. This algorithm is only descriptive and does not correct reflectivities.

\footnotetext{
${ }^{4}$ See https://ta.cr.usgs.gov/GTOPO30 for more information.
} 
Each of the above quality controls comes with its own quality descriptor. For the purposes of this study, a single quality metric value per polar bin is desired for the reflectivity composites. A "total quality" indicator is therefore defined according to Ośródka et al. (2014). This metric is defined as the minimum quality among those determined in the beam blockage, attenuation, and beam broadening steps outlined above.

The processing of input polar data in this way and using the BALTRAD toolbox is already being performed in Europe (e.g., Ridal and Dahlbom 2017). Noteworthy for our study, however, besides the application of the processing and data quality framework with North American data, is that the quality controls have been used aggressively to suppress as much nonprecipitation information content as possible. This comes at the price of rejecting some real precipitation echoes, but the nature of the LHN approach makes the consequence of assimilating contaminated pixels much more detrimental than the incorrect representation of actual precipitation as "no data."

After the processing of polar data from each radar, the reflectivity composites are generated every $10 \mathrm{~min}$ on the $2.5-\mathrm{km}$ grid shown in Fig. 1 . The higher resolution of the composites relative to the $10-\mathrm{km}$ resolution of RDPS was selected to accommodate future assimilation projects at higher resolution. In generating the composite, data are selected directly from the input polar volumes with no intermediate steps. The basic product being composited is a pseudo-constant altitude plan position indicator (CAPPI) at an altitude of $1 \mathrm{~km}$. In locations where measurements from more than one radar are available, the selection criterion for choosing the input polar data is maximum data quality, as represented by the "total quality" field.

The reflectivity composites are written to the same ODIM_H5 file format as the polar volumes and contain both uncorrected and quality-controlled reflectivities. They also contain all the quality indicator fields that have been carried over from polar to Cartesian space. Figures $2 \mathrm{a}-\mathrm{c}$ show the impact of the quality controls being applied as well as the total-quality index (subsequently referred to as "the quality index") associated with this composite.

\section{b. Model-based processing}

Before the assimilation is undertaken, the $2.5-\mathrm{km}$ composites of radar reflectivity (in $\mathrm{dBZ}$ ) are converted into precipitation rates (in $\mathrm{mm} \mathrm{h}^{-1}$ ) on the 10-km RDPS grid. The purpose of this transformation is twofold: first, it simplifies the implementation of the LHN algorithm within the atmospheric model. Second, and most importantly, the interpolation to the coarser grid is adjusted to reduce the magnitude of representation errors
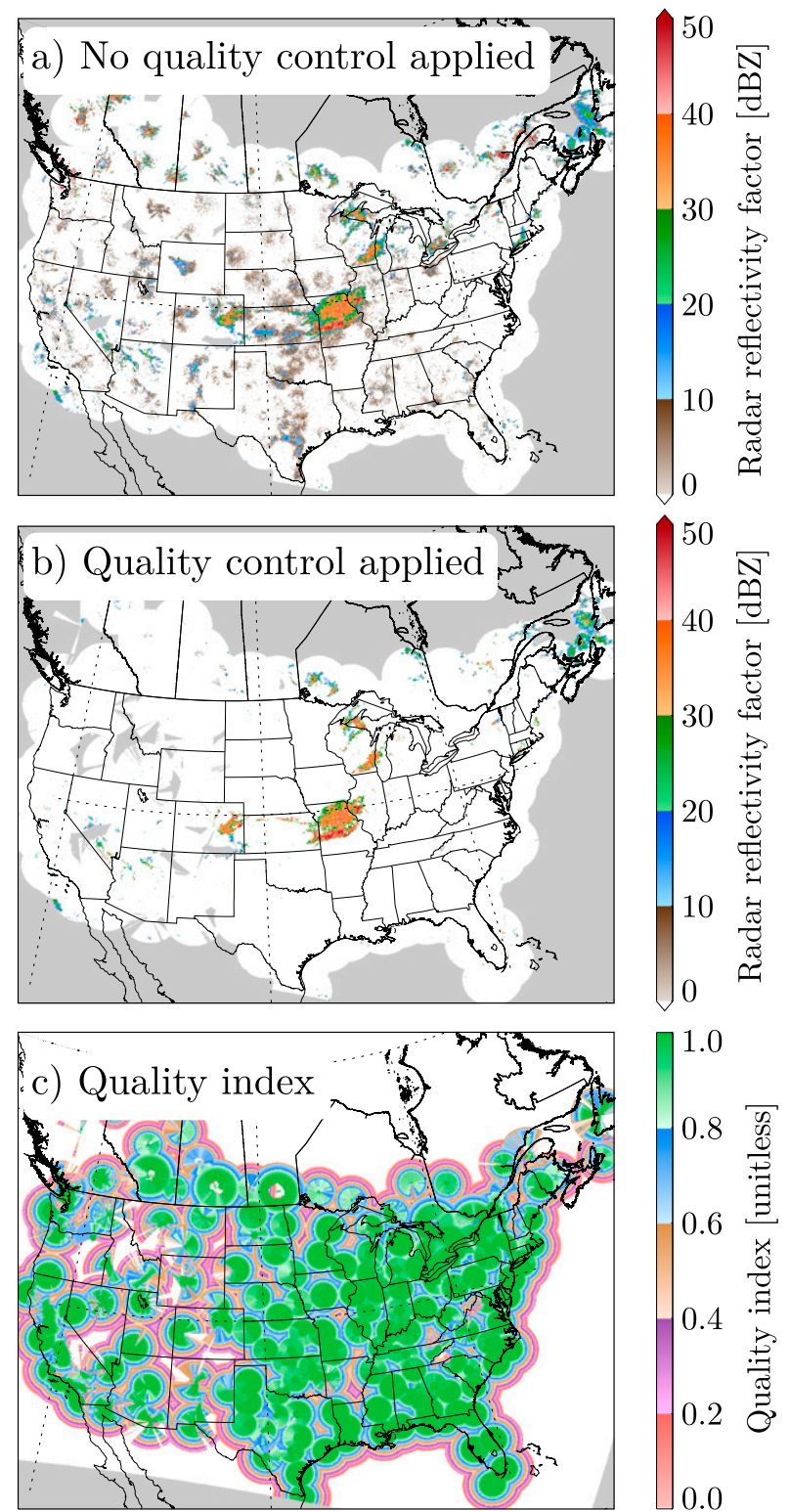

FIG. 2. Example of a reflectivity composite (valid at 0600 UTC $8 \mathrm{Jul} 2014$ ) (a) without and (b) with quality control being applied. Gray shadings indicate "no data" observations. (c) The quality index associated with each radar measurement. Values of zero appear in white.

[as described by Janjić et al. (2017)] between the observed and simulated precipitation.

Both the unit change and averaging are performed using

$$
\bar{R}_{\mathrm{mm} \mathrm{h}^{-1}}=\frac{\sum_{j=1}^{\mathrm{nj}} w_{j}^{\mathrm{qi}}\left[\frac{10^{\left(\mathrm{dB} Z_{j} / 16\right)}}{27.4248}\right]}{\sum_{j=1}^{\mathrm{nj}} w_{j}^{\mathrm{qi}}}
$$


where $\mathrm{dB} Z_{j}$ represents the individual radar reflectivity measurements $(j=1,2, \ldots, \mathrm{nj})$ contributing to a given average. The quantity $w_{j}^{\mathrm{qi}}$ represents the quality index (discussed in section $2 \mathrm{a}$ and illustrated in Fig. 2c) associated with $\mathrm{dB} Z_{j}$.

The bracketed part of this equation represents the conversion of radar reflectivities into precipitation rates. The coefficients used for this conversion are obtained by considering that

$$
\mathrm{dB} Z=10 \log _{10}\left(\frac{Z}{1 \mathrm{~mm}^{6} \mathrm{~m}^{-3}}\right),
$$

in combination with the well-known Marshall and Palmer (1948) $Z-R$ relationship

$$
Z=200 R^{1.6}
$$

with $Z$ expressed in units of $\mathrm{mm}^{6} \mathrm{~m}^{-3}$.

Because of the large domain used in this study, the reflectivity composites encompass a number of different climatic regions and usually contain precipitation from many types of weather phenomena. It is therefore unlikely that the simple $Z-R$ relationship of Eq. (3) will be appropriate everywhere and all the time. Nevertheless, this relation was used in this first attempt at radar assimilation. This choice, motivated by simplicity, allows LHN to stimulate precipitation in the right location and with approximately the right intensity.

In Eq. (1), the weighting of radar measurements by their associated quality index increases the influence of "good" observations in the resulting average. It also ensures that "no data" observations (which are associated with a quality index of zero) have no influence on the result. To ensure some consistency in the averaged product, it was required that a minimum of nine radar measurements with a quality index greater than 0.1 be available. If this criterion was not met, the average was marked as "no data" and given a quality index of zero. Further, to remove speckle, it was required that at least nine pixels have reflectivities greater than $15 \mathrm{~dB} Z$ for the average to be computed. Otherwise, the average was assigned a value of "undetect."

The quality indexes are themselves carried through the averaging process using

$$
\overline{w_{\mathrm{qi}}}=\frac{\sum_{j=1}^{\mathrm{nj}}\left(w_{j}^{\mathrm{qi}}\right)^{2}}{\sum_{j=1}^{\mathrm{nj}} w_{j}^{\mathrm{qi}}} .
$$

Now that the unit conversion has been covered, we give some details on the process by which the radar measurements [the $\mathrm{dB} Z_{j}$ of Eq. (1)] are chosen for a given average.
The problem is to interpolate the $2.5-\mathrm{km}$ radar measurements (the blue grid in Fig. 3a) onto the $10-\mathrm{km}$ RDPS grid (in orange). In the context of data assimilation, it is desirable to smooth radar observations to remove the small-scale features that are present in the measurements but that the model is incapable of representing. It is known (Skamarock 2004; among others) that the effective resolution of atmospheric models is lower than the resolution of their grids. Because of this, the radar measurements need to be averaged over an area larger than the $10-\mathrm{km}$ grid tiles.

The effective resolution of the RDPS's instantaneous precipitation fields was quantified by their spectral density as defined by the discrete cosine transform (Denis et al. 2002). The blue line in Fig. 3b represents the average spectrum (for the month of July 2014) of the simulated precipitation rates. We can see that this spectrum departs from a power law for wavenumber greater than 50. This indicates the model's limitations at forecasting features down to the scale of its grid size. In comparison, the spectrum of radar composites mapped to the model grid using a nearest-neighbor interpolation (the gray line in Fig. 3b) behaves as a power law down to the smallest scales.

To obtain radar data with a spectrum comparable to the model's precipitation rates, a boxcar-type filter was used to select the measurements that would contribute to a given average. All the radar observations located within a certain radius from the center of each model tiles are selected for a given average. The blue shadings in Fig. 3a illustrate the radar measurements that are located within a $12-\mathrm{km}$ radius from the center of a $10-\mathrm{km}$ model tile.

From a series of tests, it was determined that this $12-\mathrm{km}$ radius yielded the precipitation spectrum that best matched that of simulated precipitation rates. This is illustrated in Fig. 3b, where the spectra associated with radius of $10 \mathrm{~km}$ are also shown.

A side effect of the smoothing process is to change the intensity distributions of precipitation. Compared with precipitation rates estimated from the $2.5-\mathrm{km}$ reflectivity composites [using Eqs. (2) and (3) and shown in Fig. 3c], the smoothed precipitation rates on the 10-km grid (Fig. 3d) have smaller intensities. Interestingly, we observed that the smoothing process made the distributions of intensities (not shown) more similar to those of the model.

\section{Assimilation systems}

The assimilation experiments were conducted in the RDPS described by Caron et al. (2015). This system operates at a resolution of $10 \mathrm{~km}$ on a domain that 

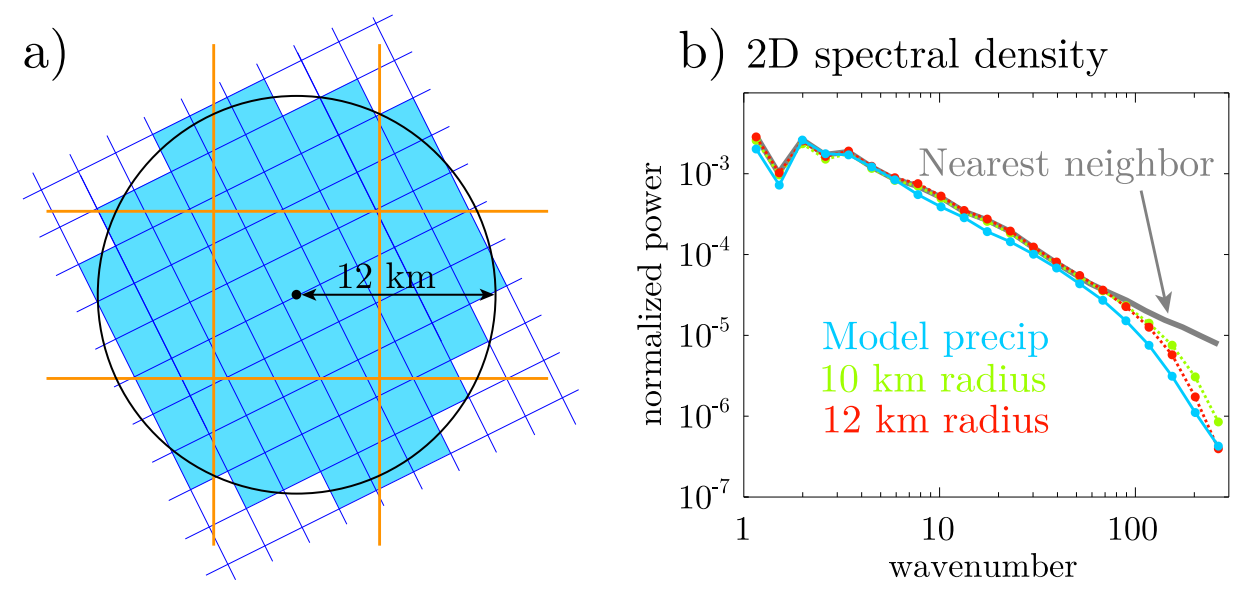

c) BALTRAD $2.5 \mathrm{~km} R=f(d B Z)$

d) smoothed $10 \mathrm{~km} R$
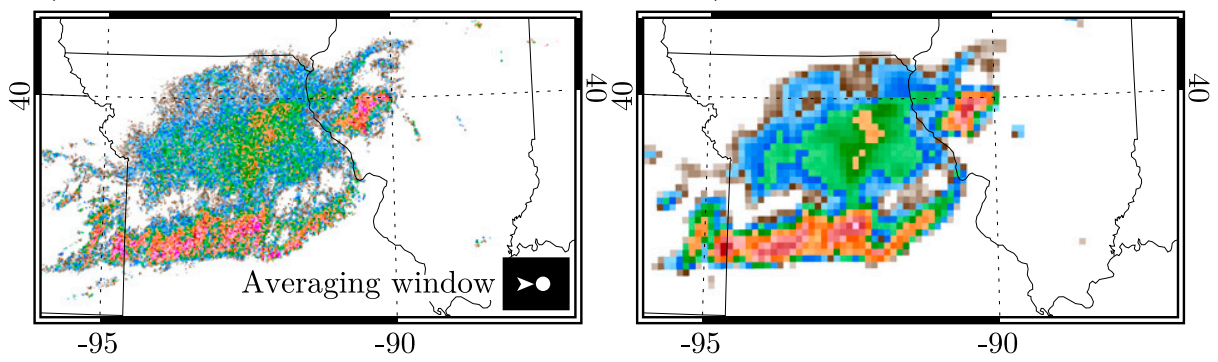

100.0

50.0

25.0

12.5 द्व

6.2

3.1

1.6

FIG. 3. Processing of radar composites before their assimilation. (a) The 2.5-km radar composites (blue grid) are smoothed and interpolated to the $10 \mathrm{-km}$ model grid (orange) by averaging all valid measurements within a radius of $12 \mathrm{~km}$ (blue shading). (b) The 2D power spectrum of the modeled precipitation rates (light blue) and radar precipitation rates obtained with averaging radii of 10 and $12 \mathrm{~km}$ (green and red, respectively). A radius of $12 \mathrm{~km}$ provides the best match with modeled precipitation. The power spectrum of radar composites obtained using nearest-neighbor selection is also shown (gray) for comparison. (c) Precipitation rates inferred from a 2.5-km BALTRAD reflectivity composite vs (d) the same data smoothed on the 10-km model grid.

extends over most of North America and surrounding waters (Fig. 1). All nonradar data are assimilated using a four-dimensional ensemble-variational (4DEnVar) approach with a 6-h assimilation window. The RDPS receives its boundary conditions from the Global Deterministic Prediction System (Buehner et al. 2015). Both the RDPS and its global counterpart have 80 staggered vertical levels that extend to $0.1 \mathrm{hPa}$. Deep and shallow convection are parameterized using the Kain-Fritsch (Kain and Fritsch 1990, 1993) and the Kuo transient (Bélair et al. 2005) schemes, respectively. The Sundqvist (1978) scheme is used for parameterizing condensation, while the MoisTKE boundary layer scheme (Bélair et al. 1999) is used for vertical diffusion.

The version of the RDPS used here differs from that described by Caron et al. (2015) in that it is a continuously cycled system in which the analysis increments are applied using an incremental analysis update (IAU; Lee et al. 2006). Figure 4 illustrates the data flow during the continuous cycle. For each assimilation cycle, the initial conditions (ICs) and background estimates (blue arrows) are provided by the previous forecast. The 4DEnVar assimilation system combines information from the background and all the nonradar observations to generate hourly analysis increments (gray arrows) during the assimilation window. These analysis increments are then applied using IAU during a 6-h period (pink boxes) from -3 to $+3 \mathrm{~h}$ from the center of the assimilation window.

In the RDPS, the control vector of the analysis includes temperature, horizontal components of the wind, $\log$ of specific humidity, and surface pressure. To reduce the spinup time after each analysis, other physical variables such as cloud contents and kinetic turbulent energy are "recycled" from the background state and used as initial conditions. This recycling reduces the spinup time and prevents issues such as the underestimation of precipitation, documented by Jacques et al. (2017a). 


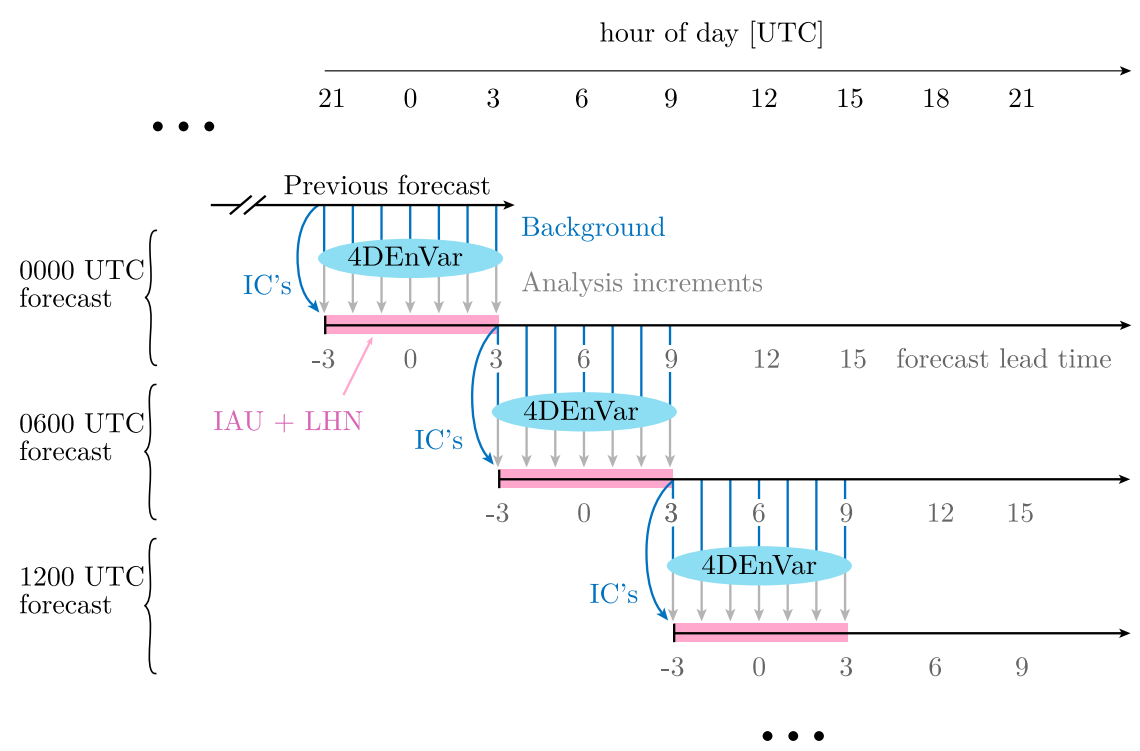

FIG. 4. Continuous cycle of the RDPS. A previous forecast (black arrows) provides the ICs for a new forecast as well as the background estimates (blue lines) for the 4DEnVar data assimilation. The analysis increments (gray arrows) produced by the assimilation system are then applied to the new forecast using IAU. It is during this 6-h period (pink boxes) that LHN is applied.

The assimilation window (pink boxes) is also when LHN is applied. ${ }^{5}$ In this study, results will be presented both during the assimilation window and during the "free" forecast that follows.

To save on computational costs, LHN experiments have been performed offline. This means that the continuously cycled RDPS had already been integrated and all the necessary ICs and analysis increments saved on disk. With this setup, unmodified reruns (i.e., without LHN) reproduce the original forecasts to machine precision.

LHN was tested by reintegrating the 0000 and 1200 UTC forecasts during the month of July 2014. This time span, combined with the size of the assimilation domain, allowed LHN to be tested on a broad range of summertime weather phenomena including, but not limited to, land-sea breeze convection, scattered showers due to cumulus development, frontal weather systems, and terrain-induced precipitation. In this study, no distinction is made among these different weather types.

\section{Nudging algorithm}

The LHN algorithm, that was implemented for this project, is similar to the one described by Jones and

\footnotetext{
${ }^{5}$ While LHN and IAU adjustments are applied during the same period, the two processes are independent from one another.
}

Macpherson (1997). The technique relies on the assumption that the precipitation rates at the surface are directly proportional to the integrated latent heat release in the column above. At a resolution of $10 \mathrm{~km}$, this assumption is expected to be valid (Stephan et al. 2008). To force a better correspondence between the precipitation rates generated by the model $\left(\mathrm{PR}_{\text {model }}\right)$ and the precipitation rates observed by the radars $\left(\mathrm{PR}_{\mathrm{radar}}\right)$, the LHN algorithm modifies the vertical profiles of temperature tendencies due to latent heat release $\dot{T}^{\mathrm{LHR}}$ such that

$$
\overline{\dot{T}_{\text {model }}^{\mathrm{LHR}}} \approx \frac{\mathrm{PR}_{\text {radar }}}{\mathrm{PR}_{\text {model }}} \dot{T}_{\text {model }}^{\mathrm{LHR}},
$$

with the hatted quantity representing the latent heating rates after the application of LHN. Throughout this article, only instantaneous precipitation rates are considered.

Because of various tuning parameters described below, it is easiest to express the action of LHN as an adjustment being added to the latent heat release already present in the model:

$$
\widehat{\dot{T}_{\text {model }}^{\mathrm{LHR}}}=\dot{T}_{\text {model }}^{\mathrm{LHR}}+\dot{T}_{\text {adjust }}^{\mathrm{LHR}} .
$$

This section describes how $\dot{T}_{\text {adjust }}^{\text {LHR }}$ is defined depending on the situation.

Figure 5 illustrates the decision tree being followed for the application of LHN at each grid point. First, the algorithm determines whether LHN must be applied. 


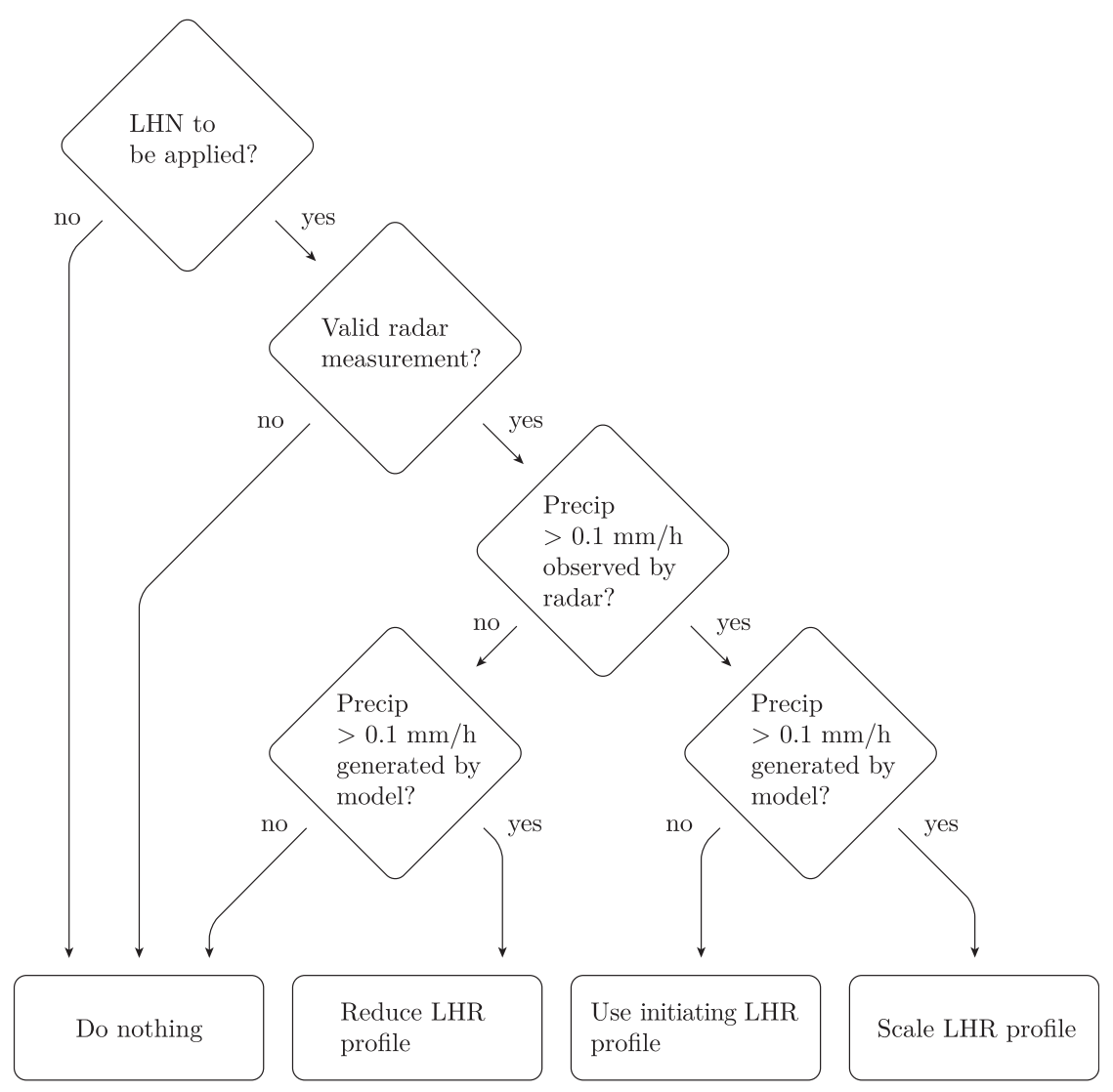

FIG. 5. Decision tree of the LHN algorithm.

As indicated in Fig. 4, LHN is only applied during a -3 to $+3 \mathrm{~h}$ window ${ }^{6}$ and where valid radar measurements are available. A given radar measurement is considered valid if its quality index is greater than 0.1 . The rest of the decision tree depends on the occurrence of simulated and/or observed precipitation.

- In the trivial case where both the modeled and radarinferred precipitation rates are $<0.1 \mathrm{~mm} \mathrm{~h}^{-1}$, nothing is done.

- When the model generates precipitation but none is observed, the temperature tendencies due to latent heat release are reduced by a constant factor $w^{r}$ such that

$$
\dot{T}_{\text {adjust }}^{\mathrm{LHR}}=\overline{w^{\mathrm{qi}}}\left(w^{r}-1\right) \dot{T}_{\text {model }}^{\mathrm{LHR}} .
$$

For our system, it was found that $w^{r}=0.5$ worked well. As suggested by Stephan et al. (2008), latent heating rates are only modified where they are positive. The quantity $\overline{w^{\mathrm{qi}}}$ comes from Eq. (4). It modulates the

\footnotetext{
${ }^{6} \mathrm{LHN}$ is not applied during the first 15 min (three model time steps) of model integration to allow "spinup" of precipitation.
}

intensity of nudging as a function of the quality of the measurement being used. Because the quality index becomes smaller with range, the presence of $w^{\mathrm{qi}}$ in Eq. (7) creates a smooth transition between the nudging applied within radar coverage and the unaffected areas elsewhere. An appreciation for the diminishing quality indicator with range can be obtained from Fig. 2c.

- Where the observed and simulated precipitation rates $>0.1 \mathrm{~mm} \mathrm{~h}^{-1}$,

$$
\dot{T}_{\text {adjust }}^{\mathrm{LHR}}=\overline{w^{\mathrm{qi}}}\left(R_{\text {ratio }}-1\right) \dot{T}_{\text {model }}^{\mathrm{LHR}},
$$

with

$$
R_{\text {ratio }}=\frac{\mathrm{PR}^{\text {radar }}}{\mathrm{PR}^{\text {model }}}
$$

To limit possible model shocks caused by strong adjustments, $R_{\text {ratio }}$ is not allowed below 0.5 or above 2 . - Finally, there is the more problematic case of grid points where precipitation is observed by the radars but is not simulated by the model. When this happens, there are no latent heating profiles to be scaled, and the above equations cannot be used. In such cases, 


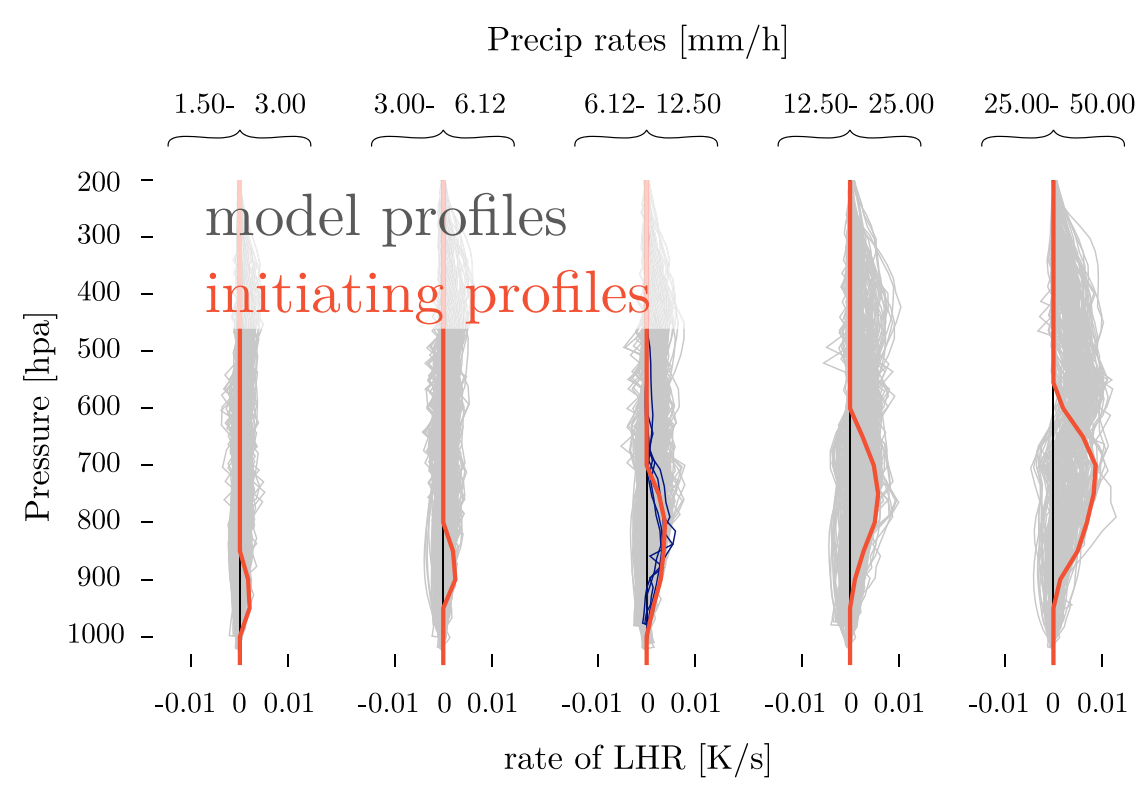

FIG. 6. "Initiating profiles" (in red) used to warm the atmosphere where the radar indicates that the model should be generating precipitation. These profiles vary depending on the precipitation rates and are based on the latent heating rates observed in the model (in gray).

Jones and Macpherson (1997) proposed to use the latent heating profile of a neighboring grid point with precipitation. In the RDPS, this approach lead to artifacts in the precipitation fields; the neighboring profiles chosen by the LHN algorithm differed from one computational tile to the next, which caused discontinuities at the boundary of the tiles.

Additional MPI communications would have eliminated this problem at the expense of higher computational costs. To avoid these costs, we chose to use predefined "initiating" profiles to stimulate the model in generating precipitation where it is observed but not simulated.

To construct these initiating profiles, we first examined the vertical profiles of temperature tendencies due to latent heating as a function of the simulated precipitation rates at the ground. Figure 6 shows a number of such profiles (thin gray lines) as a function of height (hPa) and for different intervals of precipitation intensities. Six precipitation categories have been used: the five bins shown in Fig. 6 and an additional $>50 \mathrm{~mm} \mathrm{~h}^{-1}$ category that is similar to the $25-50 \mathrm{~mm} \mathrm{~h}^{-1}$ interval.

In general, these profiles exhibit a great amount of variability. However, there is some commonality in the latent heating profiles associated with different precipitation categories. For example, Fig. 6 shows a clear relation between the maximum intensity of heating and the intensity of surface precipitation. Further, if we choose to examine only the latent heating profiles that exhibit the most low-level heating (which should be indicative of the early stages of precipitation development), then the profiles become much more similar to one another. To illustrate this, five profiles exhibiting low-level heating have been highlighted in blue for the $6.12-12.50 \mathrm{~mm} \mathrm{~h}^{-1}$ interval. After such selection, smooth and strictly positive profiles (the red curves of Fig. 6) that are representative of low-level heating were extracted visually. These profiles were used for all forecasts in this study.

A sensitivity experiment was conducted to alleviate the concern that these artificial profiles could be detrimental to the forecasts. Thirty days of LHN forecasts were performed with the intensity of the initiating profiles set to $0.75,1.0$, and 1.25 times those illustrated in Fig. 6. Following the same verification methodology as in section 6 , it was found that the forecasts obtained with 1.0 times the amplitudes shown in Fig. 6 performed best.

Figure 7 illustrates the inner workings of the LHN algorithm. Different colors are used to show which branch of the LHN decision tree (Fig. 5) is being executed at the beginning of a model integration. Areas in pink show LHN attempting to remove modeled precipitation. The locations where initiating profiles are used to stimulate precipitation are given in orange. Dark blue is used to show areas where both the radar and the model have precipitation.

The forecast shown was initiated at 0900 UTC 8 July 2014. Twenty minutes later, at 0920 UTC, the LHN algorithm is run for the first time and mostly attempts to 

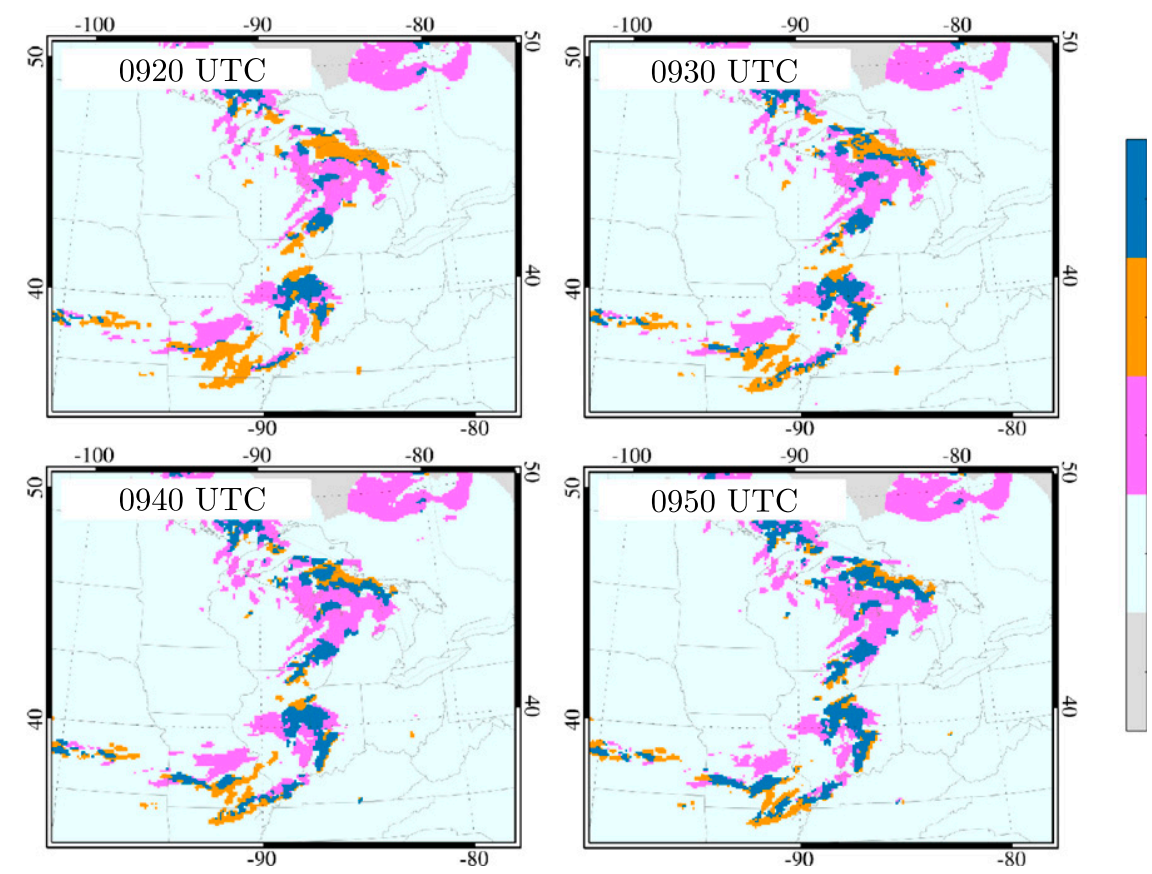

Scale LHR

profile

Use initiating

LHR profile

Reduce LHR

profile

Do nothing

no radar

FIG. 7. The inner workings of the LHN algorithm as it is applied at the beginning of a forecast. Different colors are used to illustrate which branch of the LHN algorithm (Fig. 5) is being executed at each model grid point. The first time LHN is applied (0920 UTC), initiating profiles (in orange) are used in approximately one-third of the grid points. These profiles are quite effective at stimulating the model to generate precipitation. Thirty minutes later (0950 UTC), the initiating profiles are used only at the periphery of precipitation areas.

fix the mismatches between the observed and simulated precipitation. In the majority of locations, it is reducing profiles of latent heat release (pink) or using initiating profiles (orange) to stimulate precipitation. As the model is integrated forward in time, there is a clear reduction of the extent where the initiating profiles (orange) are being used. Thirty minutes later, at 0950 UTC, initiating profiles are used only at the periphery of the precipitation areas. This behavior is typical of all forecasts and indicates that the initiating profiles are effective at generating precipitation where desired.

One of the main impacts of LHN is to remove or reduce the precipitation where it is not observed. However, because the RDPS tends to overpredict precipitation [see Fig. 7a of Fortin et al. (2015)], LHN is not as effective at removing precipitation as it is generating it. The pink area in Fig. 7 does not vary much in time, which indicates that LHN is constantly trying to reduce the precipitation in these areas. This situation prevails in all forecasts and at all times, which points to the need of reducing model biases.

One final aspect of the LHN algorithm is the adjustment of moisture. It was found beneficial to adjust the water mixing ratio such that relative humidity is conserved for the temperature changes applied by LHN. Including these adjustments extended the beneficial impact of LHN on precipitation scores by approximately $30 \mathrm{~min}$. This result may be explained by the fact that the RDPS has no components dedicated to cloud analysis [e.g., the one described by Macpherson et al. (1996)].

\section{MAPLE: Lagrangian extrapolation of radar measurements}

A natural competitor for short-term precipitation forecasts is extrapolation techniques for the nowcasting of reflectivity composites. At ECCC, the MAPLE algorithm (Germann and Zawadzki 2002) has been used operationally since 2013.

A special implementation of the MAPLE algorithm was used to allow a direct comparison with the forecasts performed here. The source data for MAPLE are the quality-controlled, $10-\mathrm{km}$ reflectivity composites that are described in section $2 \mathrm{~b}$. Motion vectors were determined from five consecutive reflectivity composites, each separated in time by $10 \mathrm{~min}$. The latest reflectivity composite available for assimilation (valid at a lead time of $+3 \mathrm{~h}$ ) is then advected using the estimated motion vectors to provide a forecast every $10 \mathrm{~min}$ for a period of $6 \mathrm{~h}$.

Compared with the integration of an atmospheric model, this nowcasting approach is not computationally expensive. Since it is initialized from a reflectivity 
All scores for precipitation rates $>1 \mathrm{~mm} / \mathrm{h}$

Average for 60 forecasts
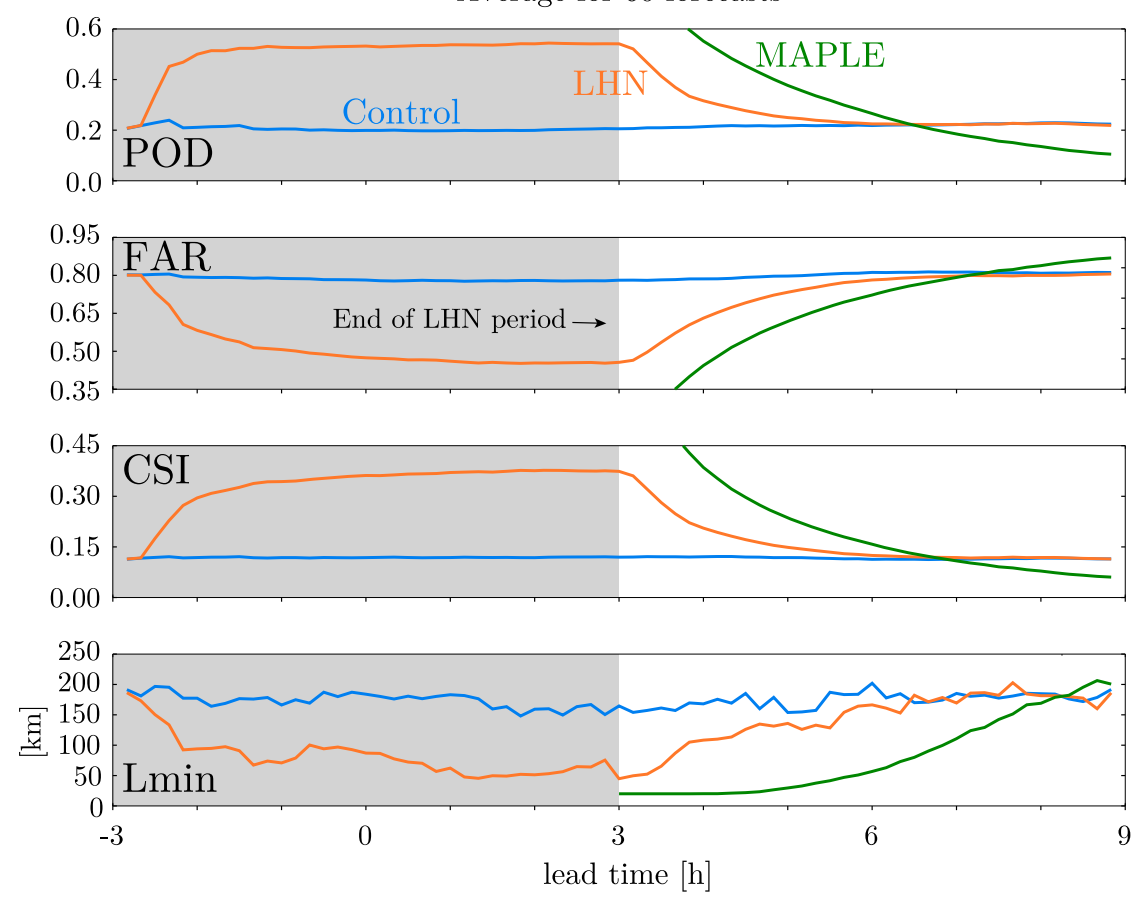

FIG. 8. Verification scores of forecasts with (orange) and without (blue) LHN. Scores of MAPLE nowcasts are shown in green.

composite, its skill is very good during the first hour. However, MAPLE allows no dynamical growth or decay of the advected precipitating areas.

\section{Results}

This section examines the average performance of LHN during the 1-month period when it was tested.

\section{a. Verification of precipitation against radar observations}

Figure 8 compares three different forecasts against the radar-inferred $10-\mathrm{km}$ precipitation rates described in section $2 b$. The forecasts are as follows:

1) The control forecasts from the RDPS without any information from the radars (in blue).

2) The forecasts with radar data assimilation by LHN (in orange).

3) MAPLE nowcasts (in green).

Four different scores are illustrated. The first three are classic contingency scores as defined by Schaefer (1990). They are the probability of detection (POD), the false alarm rate (FAR), and the critical success index (CSI). The fourth quantity displayed is the minimum radius for a skilled forecast $\left(L_{\min }\right)$ as defined by Dixon et al.
(2009) and derived from the fractions skill score (FSS; Roberts and Lean 2008). To obtain this quantity, we estimate the FSS for circular areas of increasing radius. $L_{\min }$ is the smallest radius where the FSS reaches a predetermined threshold

$$
\text { FSS }_{\text {target }}=0.5+\frac{f_{o}}{2},
$$

where $f_{o}$ is the fraction of points in the domain that exceed a predefined threshold (here, $1 \mathrm{~mm} \mathrm{~h}^{-1}$ ). This quantity provides a measure for the smallest scale at which a given forecast exhibits skill. The smaller the $L_{\mathrm{min}}$, the better the forecast.

To be considered valid, radar observations had to have a total quality index greater than 0.2 . The gray shading in Fig. 8 corresponds to the period of forced forecast where both the analysis increments and LHN are being applied. At lead times greater than $3 \mathrm{~h}$ (white background), the forecasts start to evolve freely.

The four scores depicted in Fig. 8 behave in a similar manner and show that the LHN clearly improves precipitation throughout the 6-h period of forced forecasts. However, the improvements rapidly vanish during the free forecast. After approximatively $3 \mathrm{~h}$, the skill of the LHN forecasts becomes comparable to that of the 


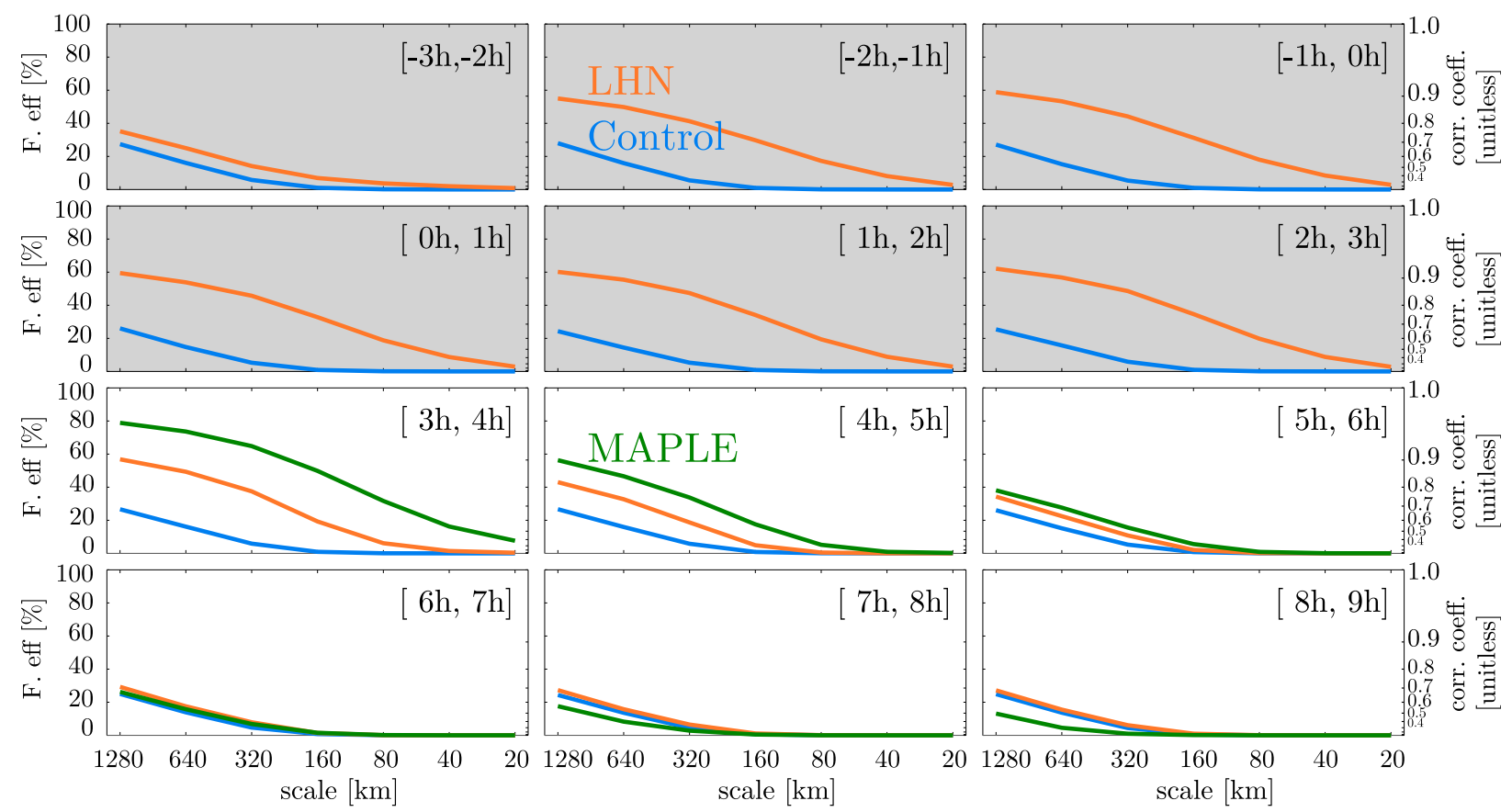

FIG. 9. Forecasting efficiency (see appendix) of bandpass forecasts of precipitation rates as a function of lead time and scale. The verification is conducted against radar composites; Haar wavelets are used for the decomposition. The skill of LHN, control, and MAPLE forecasts appear in orange, blue, and green, respectively.

control. As for MAPLE, it has an advantage over the control RDPS forecasts during approximately $4 \mathrm{~h}$.

This behavior corresponds well with the intuitive notion for forecast skill that one gets by visually comparing the forecast and observed precipitation fields (Jacques et al. 2017b).

Several variations on these scores have also been examined. Setting the thresholds for precipitation rates to 0.1 or $5 \mathrm{~mm} \mathrm{~h}^{-1}$ leads to results that are qualitatively similar to those shown here. When daytime and nighttime forecasts are separated, it is observed that the skill of 1200 UTC forecasts diminished slightly more rapidly than for the 0000 UTC forecasts. This can be explained by the fact that 1200 UTC corresponds to the beginning of the solar day, during which short-lived and small-scale convection develops and decreases predictability.

A different perspective on the application of LHN can be obtained by performing a verification method that accounts for the different scales present in the precipitation field. This is done following Surcel et al. (2014), who used Haar wavelets to decompose the simulated and observed precipitation fields into seven bandpass fields. The Pearson correlation coefficient was computed between the respective bandpass fields of the forecasts and the radar as a function of lead time.

Figure 9 shows the forecasting efficiency (a function of the Pearson correlation coefficient that is discussed in the appendix) computed during the forced forecast (indicated by a gray background) and the free forecasts (white background). We observe that scales of $20 \mathrm{~km}$, corresponding to an area of $2 \times 2$ model grid points, are not well predicted, even during the period where LHN is actively being applied. On the other hand, applying LHN consistently improves the forecasting efficiency by approximately $30 \%$ at scales larger than $160 \mathrm{~km}$ $(16 \times 16$ grid points). The improved skill maintains itself throughout the forced forecast.

During the free forecast (white background), it is interesting to consider how the relative improvement in skill brought by LHN diminishes equally fast at all scales. After $3 \mathrm{~h}$ of free forecast, the respective skill of LHN and MAPLE forecasts have become equivalent to that of the control forecasts.

\section{b. Verification of wind, temperature, and moisture}

One advantage of LHN is that the information from the precipitation field can be propagated to other state variables through the integration of the atmospheric model. In theory, bringing the precipitation rates closer to observations should also bring other variables closer to observations. It is also important to ensure that LHN does not deteriorate the RDPS's ability to predict nonradar observations (pressure, winds, moisture, etc.). 


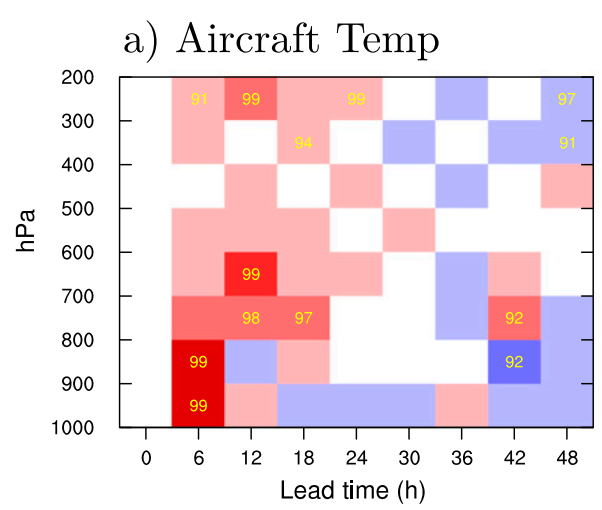

c) Radiosonde Temp

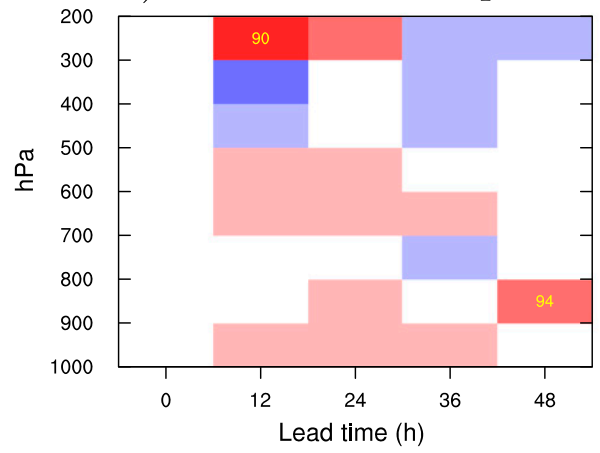

b) Aircraft U wind

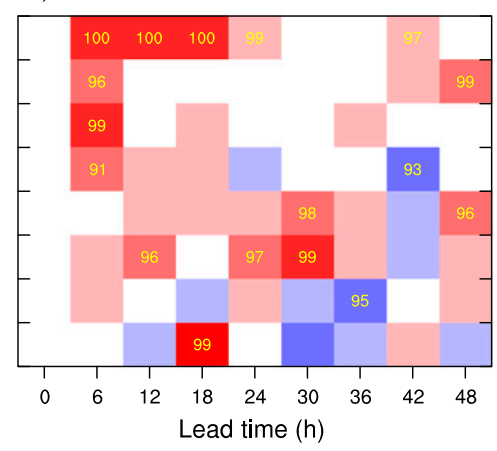

d) Radiosonde U-wind

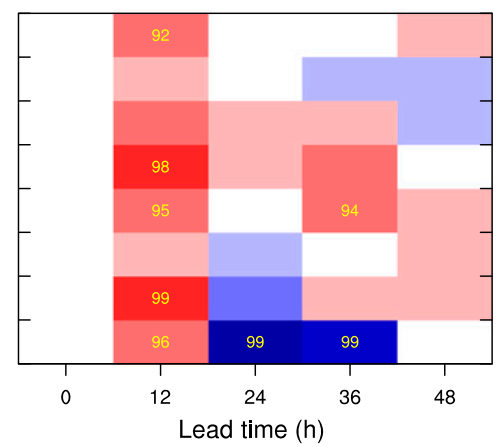

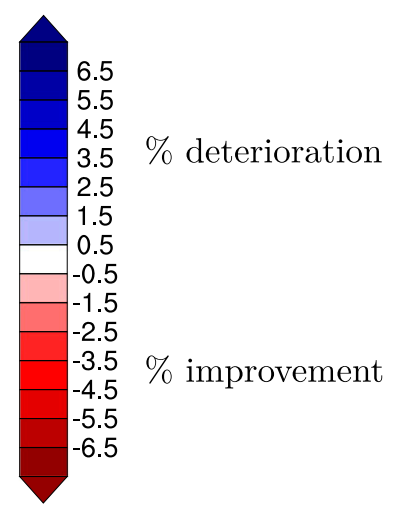

e) Radiosonde Moist

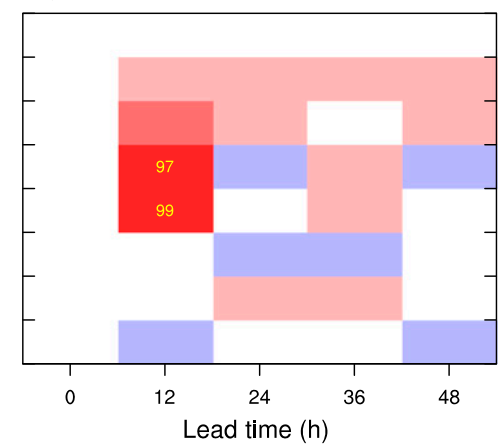

FIG. 10. Percentage difference between the RMSE of LHN forecasts and those of the control forecasts. The improvements due to the application of LHN appear in red and deteriorations in blue. The different panels represent RMSE estimated against (a) aircraft observations of temperature, (b) aircraft observations of $U$-wind velocity, (c) radiosonde observations of temperature, (d) radiosonde observations of $U$-wind velocity, and (e) radiosonde observations of dewpoint depression.

Figure 10 shows the percentage difference in rootmean-square error (RMSE) between the control and LHN forecasts. Errors are estimated against aircraft measurements (Figs. 10a,b) and radiosondes (Figs. 10c,e). Aircraft measurements are taken at all altitudes throughout the verification domain (labeled "upper air verif" in Fig. 1). However, low-level observations are concentrated to urban areas where airports are found. As for radiosondes, there are approximately 70 stations within the verification domain.

Three variables are examined: temperature (Figs. 10a,c), the $U$ component of the wind (Figs. 10b,d), and moisture (dewpoint depression; Fig. 10e). Results are presented as a function of height (in intervals of $100 \mathrm{hPa}$ ) and forecast lead time (in bins of $6 \mathrm{~h}$ for aircraft measurements and every $12 \mathrm{~h}$ for radiosondes). The color red indicates better results (smaller errors) for LHN forecasts; the color blue indicates deteriorations. For each time-height bin, an $F$ test was applied to determine the probability that the difference between the two forecasts would be different from zero. Confidence levels greater than or equal to $90 \%$ are indicated in yellow.
Overall, LHN brings RMSE improvements of approximately $2 \%$ at lead times up to $24 \mathrm{~h}$ for temperature and $U$-wind velocity. Moisture improvements are observed up to $12 \mathrm{~h}$. To put these results in perspective, we note that the magnitude of the RMSE improvements obtained here is roughly comparable to that observed for the most recent operational upgrade of the RDPS system.

One notable deterioration is observed for winds below $800 \mathrm{hPa}$ and at lead times of $24-36 \mathrm{~h}$. It is most visible in Fig. 10d, but it is also observed for the $V$ component of the wind (not shown) and, to a lesser extent, in verifications against aircraft observations in Fig. 10b. We are unsure of the reasons that could explain these deteriorations. A longer verification period would help determine whether the patterns of improvements and deteriorations are systematic. Neutral results (not shown here) were obtained when the forecasts were verified against the $10-\mathrm{m}$ winds measured by surface stations.

\section{Discussion}

At the onset of this project, we wondered if applying LHN on a continental-scale domain would help adjust 
some large-scale atmospheric features and result in improvements lasting more than a few hours. The results presented above both refute and support this supposition.

On the one hand, the skill in forecasting precipitation is rapidly lost once LHN stops being applied. When considering Fig. 8, the exponential-like decay in precipitation skill suggests that even after applying LHN on a large domain for $6 \mathrm{~h}$, the method was not successful in nurturing a dynamically balanced environment that supports the observed precipitation. The loss of skill within $3 \mathrm{~h}$ is comparable to that reported in other LHN studies, which shows that a larger assimilation domain does not automatically lead to more persistent improvements.

Moreover, considering the skill as a function of scale (in Fig. 9), it is seen that the relative improvements in precipitation forecast brought by LHN diminish equally fast at all scales. The skill of large scales appears to last longer only because it was better to start with.

On the other hand, the verification against aircraft observations shows relatively long-lived improvements throughout the atmosphere. Similar results were obtained in other assimilation systems operating on large domains. In ECMWF's 4D-VAR assimilation of radar precipitation, Lopez (2011) finds "rather neutral or slightly positive" impact on other traditional atmospheric scores. In data denial experiments, James and Benjamin (2017) also find that radar reflectivities have a small impact on other atmospheric variables. Unfortunately, it is difficult to compare these results with those obtained here because the cases, domains, and scores are different.

The fact that these improvements persist for $12-24 \mathrm{~h}$ seems to indicate that large-scale features could indeed be adjusted through the use of LHN. However, these improvements did not significantly project on the simulated precipitation.

Atmospheric moisture is directly affected by LHN, such that its beneficial effects are readily explained. However, the impact of LHN on wind forecasts is more difficult to explain, especially since the largest improvements are found high in the atmosphere. One hypothesis is that LHN improves winds through a better specification of the convergence/divergence patterns that occur as a consequence of ongoing latent heat release in the atmosphere. Another plausible explanation is that the LHN adjustments on temperature and moisture modify the atmospheric mass, which could improve high-level atmospheric winds through geostrophic adjustments.

When it comes to the comparison with simple nowcasting approaches, it can appear discouraging to see
LHN being outperformed by MAPLE. In a similar comparison, Simonin et al. (2017) find that an hourly cycled system of numerical weather prediction yields better results than extrapolation nowcasts after $1.5-2 \mathrm{~h}$. Because this comparison involves different forecasting systems over a different domain and for different cases, it is difficult to explain the difference with the results obtained here. It seems plausible, however, that the larger domain, the coarser resolution, and the 6-h assimilation cycle of our study gave an advantage to MAPLE.

Given the good performance of MAPLE, one can imagine a setup where LHN would be applied not only from observed precipitation, but also from MAPLE nowcasts. Such an avenue could be the object of future work.

\section{Conclusions}

As a first step toward operational radar data assimilation in a Canadian forecasting system, two-dimensional reflectivity composites have been assimilated using latent heat nudging (LHN). Forecasts were performed with the Regional Deterministic Prediction System (RDPS) on a 10-km grid over the North American continent and parts of the surrounding oceans. The main goal of this study was to consolidate our understanding of LHN on a large domain that allows LHN to act on a wide range of spatial scales.

At the core, the LHN technique used here is similar to the one proposed by Jones and Macpherson (1997). Latent heating rates are adjusted for a better match between the observed and modeled precipitation rates. However, this study proposes a few improvements to the original LHN approach.

One such improvement is the use of a qualitative quality index associated with each radar measurement. This quality index, whose value ranges between 0 and 1 , originates from the customized quality controls that have been applied to individual polar measurements. It is used 1) to construct the reflectivity composites, 2) to modulate the intensity of the nudging being applied, and 3) to prevent dubious measurements from being used in the forecast verification.

Another improvement is the processing of radar input so that its effective resolution matches that of the modeled precipitation.

A unique feature of this study is the processing of weather radar polar measurements into two-dimensional composites of reflectivity using the BALTRAD toolbox. It is the first time that this tool is used in a North American context (approximately 180 radars in total). This application of open source processing software 
implies that software solutions may be transferred to other continents, file formats, and radar frequencies. It also highlights that weather radar data from North America (this study) and Europe (Ridal and Dahlbom 2017) indicate potential for harmonized representation and quality controls according to open science principles across continents.

A total of 60 forecasts have been evaluated during the month of July 2014. In verifications against radar observations, it is shown that $\mathrm{LHN}$ is able to improve forecasts of instantaneous precipitation rates for lead times up to $3 \mathrm{~h}$. In comparison, simple extrapolation nowcasts by the MAPLE algorithm were able to outperform modeled precipitation rates for lead times up to $4 \mathrm{~h}$.

A verification technique involving wavelet decompositions was also used to assess the forecast skill as a function scale and lead time. Such representation shows that the relative improvement in skill brought by the LHN decreases equally rapidly at all scales.

Verifications against aircraft observations revealed small $(\approx 2 \%)$ but statistically significant improvements in root-mean-square errors (RMSE) due to the application of LHN. These results can be seen at a majority of vertical levels and at lead times extending between 12 and $24 \mathrm{~h}$, depending on the variable.

In future work, we plan on using information on radar observation height within the algorithm. The implementation of LHN in a $2.5-\mathrm{km}$ version of the Canadian regional model and a better use of the quality index will also be investigated. In parallel, work has already begun toward the real-time monitoring of the North American BALTRAD composites. This effort should result in better calibration for the Canadian radars as well as improvements in the $Z-R$ relationships being used.

Now that the infrastructure for processing radar data has been put in place, the assimilation of Doppler velocity in the variational system will be pursued along with other methodologies for assimilating radar measurements.

Acknowledgments. The authors of this study are committed to ensuring that this work adheres to minimal Open Science requirements. The following measures have been put in place to increase transparency and, to a certain extent, reproducibility of the results that are presented here. 1) The reflectivity composites and forecasts used in this study have been archived for long-term storage and are available upon request. 2) The software used for the quality control of input radar data, including the generation of Cartesian composites, is the BALTRAD toolbox: http://git.baltrad.eu/. 3) For the most part, the software used for the postprocessing of radar data, the verification, and the generation of figures has been written in the IDL language. The source code for these routines is made available at https://github.com/dja001/idl_ code_manuscript_lhn. 4) The Python ARM Radar Toolkit (Py-ART) is available at http://arm-doe.github. io/pyart/. The authors wish to thank Marc Verville for providing a special implementation of the MAPLE nowcasting system for this project. Thanks also to Thomas Milewski for his help with the RDPS and to Michèle de la Chevrotière and Weiguang Chang for fruitful discussions on the concept of forecasting efficiency. Finally, Peter Houtekamer is thanked for providing a detailed review of an earlier version of this manuscript.

\section{APPENDIX}

\section{Forecasting Efficiency}

In this appendix, we motivate the choice of the "forecasting efficiency" as a quantity of interest in the context of forecast verification.

In section $6 \mathrm{a}$, the performance of different forecasts as a function spatial scale was assessed. Precipitation rates have been decomposed using Haar wavelets, and the Pearson correlation coefficient $\rho$ was computed between the respective bandpass decompositions of the forecasts and the radar observations. Figure A1 illustrates the result of such computations during the first hour of free forecast. From this figure, we may conclude that the LHN forecasts (orange) perform better than the control forecasts (blue) at scales between 160 and $640 \mathrm{~km}$. Similarly, the MAPLE forecasts (green) appear to do only slightly better than the LHN forecasts at scales larger than $320 \mathrm{~km}$.

The problem with the above conclusions is that we usually think of a "good" forecast as having small errors, compared with observations. Because $\rho$ is nonlinearly related to the magnitude of errors made by a model, inferring the forecast quality from $\rho$ is difficult.

To appreciate this, we can use the general framework for least squares estimation [as in Myers (1990), and other reference textbooks]. Let

$$
\mathbf{y}=\hat{\mathbf{y}}+\mathbf{e},
$$

with $\mathbf{y}$ representing an array of dependent variables, $\hat{\mathbf{y}}$ an array of estimates by a linear model, and $\mathbf{e}$ the residual errors.

Assuming no correlation between $\hat{\mathbf{y}}$ and $\mathbf{e}$,

$$
\begin{aligned}
\operatorname{VAR}(\mathbf{y}) & =\operatorname{VAR}(\hat{\mathbf{y}})+\operatorname{VAR}(\mathbf{e}), \\
\mathrm{TSS} & =\mathrm{ESS}+\mathrm{SSR} .
\end{aligned}
$$



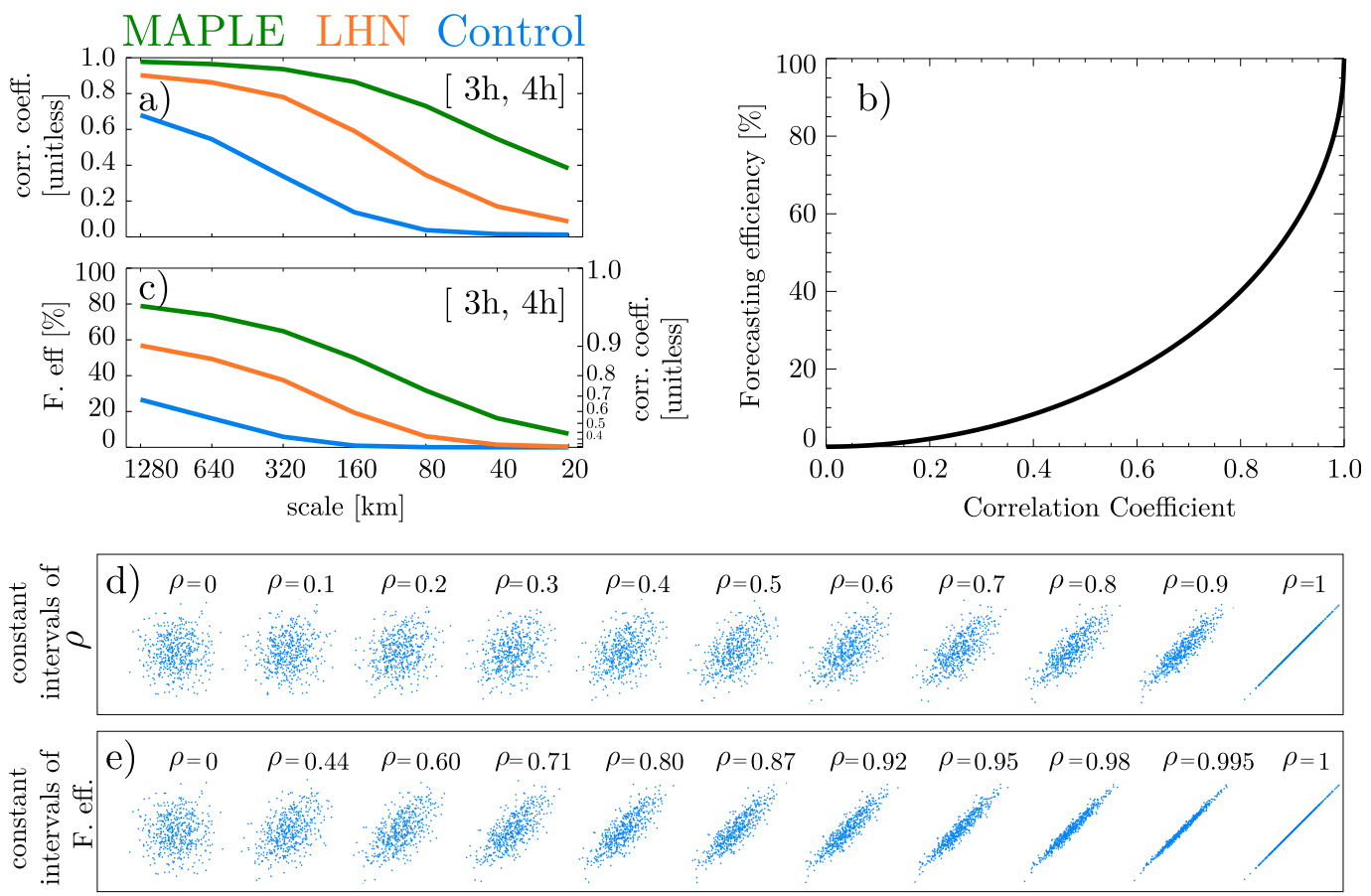

FIG. A1. (a) Correlation coefficients of scale-decomposed forecasts and radar composites (described in section 6a). (b) Forecasting efficiency as a function of the Pearson correlation coefficient. (c) As in (a), but the forecasting efficiency is plotted instead of the correlation coefficient. (d) Scatterplots showing a constant progression of the correlation coefficient $(\rho=0,0.1,0.2,0.3, \ldots)$. (e) Scatterplots showing a constant progression of the forecasting efficiency (Forecasting efficiency $=0 \%, 10 \%, 20 \%, 30 \%, \ldots)$.

Here, TSS stands for total sum squared, ESS is the explained sum of squares, and SSR is the sum of squared residuals.

Using the "coefficient of determination"

$$
R^{2}=\frac{\mathrm{ESS}}{\mathrm{TSS}}=1-\frac{\mathrm{SRR}}{\mathrm{TSS}},
$$

and knowing that $R^{2}=\rho^{2}$, we can derive an expression for the "forecasting efficiency" (Hull 1927):

$$
\begin{aligned}
\text { Forecasting efficiency }(\%) & =100 \times \frac{\sqrt{\mathrm{TSS}}-\sqrt{\mathrm{SRR}}}{\sqrt{\mathrm{TSS}}} \\
& =100 \times\left(1-\sqrt{1-\rho^{2}}\right),
\end{aligned}
$$

which represents the percentage reduction in forecast error that is obtained by use of a linear model fitted to a cloud of points with correlation $\rho$.

The relation between $\rho$ and the forecasting efficiency is illustrated in Fig. A1b. Commenting on this relation, Hull (1927, p. 335) expressed his stupefaction at the fact that "the forecasting efficiency rises as much between correlations .98 and 1.00 (20 points) as it does between zero and .60!"”
Figures A1d and A1e are provided as additional motivation for using the forecasting efficiency in a verification context. In Fig. A1d, clouds of points with regularly increasing correlation coefficient $(\rho=0,0.1,0.2, \ldots)$ are depicted. It can be observed that the differences in scatter, which matches our intuitive notion of a "good" forecast, do not vary linearly as a function of correlation. Very little difference can be observed for $\rho<0.4$; the differences are notable for $\rho>0$.8. In Fig. A1e, clouds of points are shown for regularly increasing forecasting efficiency $(0 \%, 10 \%$, $20 \%, \ldots)$. With this progression, the differences in scatter better correspond to what we would think of as a regular progression of increasingly better forecasts.

The nonlinear relation between $\rho$ and the forecasting efficiency complicates the interpretation of Fig. A1a. At the large scales, the correlation coefficients of the MAPLE forecasts (green) are only slightly superior to those of the LHN forecasts (orange). However, as noted above, for large correlation coefficient, small changes in $\rho$ will be associated with large reduction of forecast error. Because forecast errors are of more direct interest than $\rho$, it is relevant to depict this quantity in our verification.

Figure A1c shows the same data as Fig. A1a, but this time, the forecasting efficiency is shown instead of $\rho$. 
This transformation acts as a stretching of the vertical axis for larger value of $\rho$ (see the right axis). It can be observed that the forecasting efficiency behaves similarly for the three precipitation forecasts. It is seen that the LHN forecasts bring the same improvements ( $30 \%)$ at all scales larger than $320 \mathrm{~km}$. Similarly, the MAPLE forecasts are systematically better than the LHN forecasts at scales larger than $80 \mathrm{~km}$.

\section{REFERENCES}

Alexander, C., D. Dowell, M. Hu, T. Ladwig, S. Weygandt, and S. G. Benjamin, 2017: Expanding use of radar data in deterministic and ensemble data assimilation for the High-Resolution Rapid Refresh (HRRR). 38th Conf. on Radar Meteorology, Chicago, IL, Amer. Meteor. Soc., 19B.2, https://ams.confex.com/ ams/38RADAR/webprogram/Paper321169.html.

Ballard, S. P., Z. Li, D. Simonin, and J.-F. Caron, 2016: Performance of 4D-Var NWP-based nowcasting of precipitation at the Met Office for summer 2012. Quart. J. Roy. Meteor. Soc., 142, 472-487, https://doi.org/10.1002/qj.2665.

Battan, L. J., 1973: Radar Observation of the Atmosphere. University of Chicago Press, $324 \mathrm{pp}$.

Bélair, S., J. Mailhot, J. W. Strapp, and J. I. MacPherson, 1999: An examination of local versus nonlocal aspects of a TKE-based boundary layer scheme in clear convective conditions. J. Appl. Meteor., 38, 1499-1518, https://doi.org/10.1175/ 1520-0450(1999)038<1499:AEOLVN>2.0.CO;2.

C. Girard, and P. Vaillancourt, 2005: Boundary layer and shallow cumulus clouds in a medium-range forecast of a large-scale weather system. Mon. Wea. Rev., 133, 1938-1960, https://doi.org/10.1175/MWR2958.1.

Bick, T., and Coauthors, 2016: Assimilation of 3D radar reflectivities with an ensemble Kalman filter on the convective scale. Quart. J. Roy. Meteor. Soc., 142, 1490-1504, https:// doi.org/10.1002/qj.2751.

Buehner, M., and Coauthors, 2015: Implementation of deterministic weather forecasting systems based on ensemblevariational data assimilation at Environment Canada. Part I: The global system. Mon. Wea. Rev., 143, 2532-2559, https:// doi.org/10.1175/MWR-D-14-00354.1.

Caron, J.-F., T. Milewski, M. Buehner, L. Fillion, M. Reszka, S. Macpherson, and J. St-James, 2015: Implementation of deterministic weather forecasting systems based on ensemblevariational data assimilation at Environment Canada. Part II: The regional system. Mon. Wea. Rev., 143, 2560-2580, https:// doi.org/10.1175/MWR-D-14-00353.1.

Chung, K.-S., I. Zawadzki, M. K. Yau, and L. Fillion, 2009: Short-term forecasting of a midlatitude convective storm by the assimilation of single-Doppler radar observations. Mon. Wea. Rev., 137, 4115-4135, https://doi.org/10.1175/ 2009MWR2731.1.

_- W. Chang, L. Fillion, and M. Tanguay, 2013: Examination of situation-dependent background error covariances at the convective scale in the context of the ensemble Kalman filter. Mon. Wea. Rev., 141, 3369-3387, https://doi.org/10.1175/ MWR-D-12-00353.1.

Davolio, S., and A. Buzzi, 2004: A nudging scheme for the assimilation of precipitation data into a mesoscale model. Wea. Forecasting, 19, 855-871, https://doi.org/10.1175/1520-0434(2004)019<0855: ANSFTA $>2.0 . \mathrm{CO} ; 2$.
Denis, B., J. Côté, and R. Laprise, 2002: Spectral decomposition of two-dimensional atmospheric fields on limited-area domains using the discrete cosine transform (DCT). Mon. Wea. Rev., 130, 1812-1829, https://doi.org/10.1175/1520-0493(2002)130<1812: SDOTDA $>2.0 . \mathrm{CO} ; 2$.

Dixon, M., Z. Li, H. Lean, N. Roberts, and S. Ballard, 2009: Impact of data assimilation on forecasting convection over the United Kingdom using a high-resolution version of the Met Office Unified Model. Mon. Wea. Rev., 137, 1562-1584, https:// doi.org/10.1175/2008MWR2561.1.

Douglas, R., 1990: The Stormy Weather Group (Canada). Radar in Meteorology, D. Atlas, Ed., Amer. Meteor. Soc., 61-68, https://doi.org/10.1007/978-1-935704-15-7_8.

Doviak, R. J., and D. S. Zrnić, 1993: Doppler Radar and Weather Observations. 2nd ed. Academic Press, 562 pp.

Errico, R. M., P. Bauer, and J.-F. Mahfouf, 2007: Issues regarding the assimilation of cloud and precipitation data. J. Atmos. Sci., 64, 3785-3798, https://doi.org/10.1175/2006JAS2044.1.

Fabry, F., 2015: Radar Meteorology: Principles and Practice. Cambridge University Press, 256 pp.

Fortin, V., G. Roy, N. Donaldson, and A. Mahidjiba, 2015: Assimilation of radar quantitative precipitation estimations in the Canadian Precipitation Analysis (CaPA). J. Hydrol., 531, 296-307, https://doi.org/10.1016/j.jhydrol.2015.08.003.

Germann, U., and I. Zawadzki, 2002: Scale-dependence of the predictability of precipitation from continental radar images. Part I: Description of the methodology. Mon. Wea. Rev., 130, 2859-2873, https://doi.org/10.1175/1520-0493(2002)130<2859: $\mathrm{SDOTPO}>2.0 . \mathrm{CO} ; 2$.

Helmus, J. J., and S. M. Collis, 2016: The Python ARM Radar Toolkit (Py-ART), a library for working with weather radar data in the Python programming language. J. Open Res. Software, 4, e25, https://doi.org/10.5334/jors.119.

Hull, C. L., 1927: The correlation coefficient and its prognostic significance. J. Educ. Res., 15, 327-338, https://doi.org/10.1080/ 00220671.1927.10879751.

Jacques, D., and I. Zawadzki, 2015: The impacts of representing the correlation of errors in radar data assimilation. Part II: Model output as background estimates. Mon. Wea. Rev., 143, 26372656, https://doi.org/10.1175/MWR-D-14-00243.1.

- W. Whang, S.-J. Baek, T. Milewski, L. Fillion, K.-S. Chung, and H. Ritchie, 2017a: Developing a convective-scale EnKF data assimilation system for the Canadian MEOPAR project. Mon. Wea. Rev., 145, 1473-1494, https://doi.org/10.1175/ MWR-D-16-0135.1.

— D. B. Michelson, and L. Fillion, 2017b: Implementing the latent heat nudging (LHN) algorithm in the Canadian Regional Deterministic Prediction System (RDPS). 38th Conf. on Radar Meteorology, Chicago, IL, Amer. Meteor. Soc., 19B.7, https://ams.confex.com/ams/38RADAR/webprogram/ Paper320749.html.

James, E. P., and S. G. Benjamin, 2017: Observation system experiments with the hourly updating Rapid Refresh model using GSI hybrid ensemble-variational data assimilation. Mon. Wea. Rev., 145, 2897-2918, https://doi.org/10.1175/ MWR-D-16-0398.1.

Janjić, T., and Coauthors, 2017: On the representation error in data assimilation. Quart. J. Roy. Meteor. Soc., 144, 1257-1278, https://doi.org/10.1002/qj.3130.

Jones, C. D., and B. Macpherson, 1997: A latent heat nudging scheme for the assimilation of precipitation data into an operational mesoscale model. Meteor. Appl., 4, 269-277, https:// doi.org/10.1017/S1350482797000522. 
Kain, J. S., and J. M. Fritsch, 1990: A one-dimensional entraining/ detraining plume model and its application in convective parameterization. J. Atmos. Sci., 47, 2784-2802, https://doi.org/ 10.1175/1520-0469(1990)047<2784:AODEPM>2.0.CO;2. , and _ 1993: Convective parameterization for mesoscale models: The Kain-Fritsch scheme. The Representation of Cumulus Convection in Numerical Models, Meteor. Monogr., No. 24, Amer. Meteor. Soc., 165-170, https://doi.org/10.1007/ 978-1-935704-13-3_16.

Lee, M.-S., Y.-H. Kuo, D. M. Barker, and E. Lim, 2006: Incremental analysis updates initialization technique applied to 10-km MM5 and MM5 3DVAR. Mon. Wea. Rev., 134, 13891404, https://doi.org/10.1175/MWR3129.1.

Leuenberger, D., and A. Rossa, 2007: Revisiting the latent heat nudging scheme for the rainfall assimilation of a simulated convective storm. Meteor. Atmos. Phys., 98, 195-215, https:// doi.org/10.1007/s00703-007-0260-9.

Lopez, P., 2011: Direct 4D-Var assimilation of NCEP stage IV radar and gauge precipitation data at ECMWF. Mon. Wea. Rev., 139, 2098-2116, https://doi.org/10.1175/2010MWR3565.1.

— , and P. Bauer, 2007: "1D+4DVAR" assimilation of NCEP stage-IV radar and gauge hourly precipitation data at ECMWF. Mon. Wea. Rev., 135, 2506-2524, https://doi.org/ 10.1175/MWR3409.1.

Macpherson, B., B. J. Wright, W. H. Hand, and A. J. Maycock, 1996: The impact of MOPS moisture data in the U.K. Meteorological Office mesoscale data assimilation scheme. Mon. Wea. Rev., 124, 1746-1766, https://doi.org/10.1175/1520-0493 (1996)124<1746:TIOMMD>2.0.CO;2.

Manobianco, J., S. Koch, V. M. Karyampudi, and A. J. Negri, 1994: The impact of assimilating satellite-derived precipitation rates on numerical simulations of the ERICA IOP 4 cyclone. Mon. Wea. Rev., 122, 341-365, https://doi.org/ 10.1175/1520-0493(1994)122<0341:TIOASD>2.0.CO;2.

Marshall, J. S., and W. M. K. Palmer, 1948: The distribution of raindrops with size. J. Meteor., 5, 165-166, https://doi.org/ 10.1175/1520-0469(1948)005<0165:TDORWS $>2.0$. CO;2.

Michelson, D. B., R. Lewandowski, M. Szewczykowski, H. Beekhuis, and G. Haase, 2014: EUMETNET OPERA weather radar information model implementation with the HDF5 file format. EUMETNET OPERA Rep., 42 pp., http://eumetnet.eu/ wp-content/uploads/2017/01/OPERA_hdf_description_2014.pdf.

- , and Coauthors, 2018: BALTRAD advanced weather radar networking. J. Open Res. Software, 6, 12, http://doi.org/10.5334/ jors.193.

Myers, R., 1990: Classical and Modern Regression with Applications. Duxbury/Thompson Learning, 488 pp.

Ośródka, K., J. Szturc, and A. Jurczyk, 2014: Chain of data quality algorithms for 3-D single-polarization radar reflectivity (RADVOL-QC system). Meteor. Appl., 21, 256-270, https:// doi.org/10.1002/met.1323.

Peura, M., 2002: Computer vision methods for anomaly removal. Proc. ERAD (2002), Delft, Netherlands, Copernicus GmbH, 312-317, https://www.copernicus.org/erad/online/ erad-312.pdf.

Ridal, M., and M. Dahlbom, 2017: Assimilation of multinational radar reflectivity data in a mesoscale model: A proof of concept. J. Appl. Meteor. Climatol., 56, 1739-1751, https://doi.org/ 10.1175/JAMC-D-16-0247.1.

Roberts, N. M., and H. W. Lean, 2008: Scale-selective verification of rainfall accumulations from high-resolution forecasts of convective events. Mon. Wea. Rev., 136, 78-97, https://doi.org/ 10.1175/2007MWR2123.1.
Ruzanski, E., V. Chandrasekar, and Y. Wang, 2011: The CASA nowcasting system. J. Atmos. Oceanic Technol., 28, 640-655, https://doi.org/10.1175/2011JTECHA1496.1.

Schaefer, J. T., 1990: The critical success index as an indicator of warning skill. Wea. Forecasting, 5, 570-575, https://doi.org/ 10.1175/1520-0434(1990)005<0570:TCSIAA > 2.0.CO;2.

Simonin, D., C. Pierce, N. Roberts, S. P. Ballard, and Z. Li, 2017: Performance of Met Office hourly cycling NWP-based nowcasting for precipitation forecasts. Quart. J. Roy. Meteor. Soc., 143, 2862-2873, https://doi.org/10.1002/qj.3136.

Skamarock, W. C., 2004: Evaluating mesoscale NWP models using kinetic energy spectra. Mon. Wea. Rev., 132, 3019-3032, https://doi.org/10.1175/MWR2830.1.

Stephan, K., S. Klink, and C. Schraff, 2008: Assimilation of radarderived rain rates into the convective-scale model COSMO-DE at DWD. Quart. J. Roy. Meteor. Soc., 134, 1315-1326, https:// doi.org/10.1002/qj.269.

Sun, J., 2005: Convective-scale assimilation of radar data: Progress and challenges. Quart. J. Roy. Meteor. Soc., 131, 3439-3463, https://doi.org/10.1256/qj.05.149.

- and N. A. Crook, 1997: Dynamical and microphysical retrieval from Doppler radar observations using a cloud model and its adjoint. Part I: Model development and simulated data experiments. J. Atmos. Sci., 54, 1642-1661, https://doi.org/ 10.1175/1520-0469(1997)054<1642:DAMRFD>2.0.CO;2.

__, and —_, 1998: Dynamical and microphysical retrieval from Doppler radar observations using a cloud model and its adjoint. Part II: Retrieval experiments of an observed Florida convective storm. J. Atmos. Sci., 55, 835-852, https:// doi.org/10.1175/1520-0469(1998)055<0835:DAMRFD>2.0. $\mathrm{CO} ; 2$.

_- and Coauthors, 2014: Use of NWP for nowcasting convective precipitation: Recent progress and challenges. Bull. Amer. Meteor. Soc., 95, 409-426, https://doi.org/10.1175/ BAMS-D-11-00263.1.

Sundqvist, H., 1978: A parameterization scheme for nonconvective condensation including prediction of cloud water content. Quart. J. Roy. Meteor. Soc., 104, 677-690, https://doi.org/10.1002/qj.49710444110.

Surcel, M., I. Zawadzki, and M. K. Yau, 2014: On the filtering properties of ensemble averaging for storm-scale precipitation forecasts. Mon. Wea. Rev., 142, 1093-1105, https://doi.org/ 10.1175/MWR-D-13-00134.1.

Turner, B. J., I. Zawadzki, and U. Germann, 2004: Predictability of precipitation from continental radar images. Part III: Operational nowcasting implementation (MAPLE). J. Appl. Meteor., 43, 231-248, https://doi.org/10.1175/1520-0450(2004)043<0231: POPFCR $>2.0 . \mathrm{CO} ; 2$.

Wang, M., M. Xue, K. Zhao, and J. Dong, 2014: Assimilation of T-TREC-retrieved winds from single-Doppler radar with an ensemble Kalman filter for the forecast of Typhoon Jangmi (2008). Mon. Wea. Rev., 142, 1892-1907, https://doi.org/ 10.1175/MWR-D-13-00387.1.

Wang, W., and T. T. Warner, 1988: Use of four-dimensional data assimilation by Newtonian relaxation and latent-heat forcing to improve a mesoscale-model precipitation forecast: A case study. Mon. Wea. Rev., 116, 2593-2613, https://doi.org/ 10.1175/1520-0493(1988)116<2593:UOFDDA > 2.0.CO;2.

Wattrelot, E., O. Caumont, and J.-F. Mahfouf, 2014: Operational implementation of the $1 \mathrm{D}+3 \mathrm{D}-\mathrm{Var}$ assimilation method of radar reflectivity data in the AROME model. Mon. Wea. Rev., 142, 1852-1873, https://doi.org/10.1175/ MWR-D-13-00230.1. 
Weygandt, S., and S. G. Benjamin, 2007: Radar reflectivity-based initialization of precipitation systems using a diabatic digital filter within the rapid update cycle. 22nd Conf. on Weather Analysis and Forecasting/18th Conf. on Numerical Weather Prediction, Park City, UT, Amer. Meteor. Soc., 1B.7, https://ams.confex.com/ ams/22WAF18NWP/techprogram/paper_124540.htm.

, — - T. G. Smirnova, and J. M. Brown, 2008: Assimilation of radar reflectivity data using a diabatic digital filter within the rapid update cycle. 12th Conf. on IOAS-AOLS, New Orleans, LA, Amer. Meteor. Soc., 8.4, https://ams.confex.com/ams/ 88Annual/techprogram/paper_134081.htm.

Wilson, J. W., Y. Feng, M. Chen, and R. D. Roberts, 2010: Nowcasting challenges during the Beijing Olympics: Successes, failures, and implications for future nowcasting systems. Wea. Forecasting, 25, 1691-1714, https://doi.org/ 10.1175/2010WAF2222417.1. 